\title{
Part Two: The Film Experience
}

\section{Chapter I: Filmic Consciousness Faced with Its Object}

We have tried to explain the major principles that should guide our understanding of the general phenomena of perception and identification. It has thus become easier to broach the problems relating to the particular case of the film experience.

We should rapidly recognize the path we are going to take. Film presents itself above all as an object of perception and, as such, it is a structure, a perceptual 'gestalt.' It is thus as a form, or a 'gestalt' that we will initially envisage film. But we will not linger very long on this point because we will soon perceive that film solicits a different attitude in our consciousness than the pure perceptual attitude. We will see that, in order to clarify this particular attitude, certain writers have made of the film experience something situating itself midway between the real and the unreal. These considerations, and others, will lead us to see filmic consciousness as a variation of the major category of consciousness that constitutes the imaginary consciousness. This idea will constitute the guiding thread of our whole work.

We will attempt a description of the major aspects of the filmic attitude conceived of as an imaginary attitude and, pushing this analysis further, we will then try to explain the particular variations or modalities of this attitude.

In the end, on the basis of what this description will have taught us, we will broach the problem of spectatorial behavior, or in other words, of filmic identification.

\section{The Film as an Object of Perception}

Film is first presented as an object to be perceived. Thus, we can already apply to the perception of film what we have said of perception in general.

In perception, as we have said, the object always presents itself as a structure, a form, or a 'gestalt.' The same goes for film, which, as an object to be perceived, presents itself first as a temporal form.

Film is not, in fact, merely a sum of elementary images placed in a temporal contiguity. If we envisaged each image in particular, independently of its context, we would perceive that these isolated images do not have the same signification as when they are perceived inside a film. This is because the meaning of an image always depends on those that precede it and those that follow it - in a word, on its surroundings. 
The succession of images thus creates a new reality, irreducible to the sum of the elements employed. This means that the construction of each shot and the organization of shots into scenes, and of scenes into sequences, creates a complex visual form.

A film, as Merleau-Ponty writes:

seems to be an extremely complex form inside of which a very great number of actions and reactions are taking place at every moment. The laws of this form, moreover, are yet to be discovered, having until now only been sensed by the flair or tact of the director, who handles cinematographic language as a man manipulates syntax... ${ }^{18}$

What is valid for images is equally valid for sound. The sounds and voices that accompany a film are evidently not presented as a sum of elements more or less independent of one another, but form a sonic 'gestalt,' a sonic totality in which the elements draw their signification from their assemblage. In the end, it is still necessary to consider that, inside a film, the visual form and the sonic form are not simply juxtaposed but are composed to form an even more complex ensemble.

Merleau-Ponty continues:

A sound film movie is not a silent film embellished with words and sounds whose only function is to complete the cinematographic illusion. The bond between sound and image is much closer, and the image is transformed by the proximity of sound. This is readily apparent in the case of dubbed films, where thin people are made to speak with the voices of fat people. [...] And the union of sound and image occurs not only in each character but in the film as a whole. ${ }^{19}$

The film, as an object to be perceived, thus appears as a structure, a complex organization of visual and sonic elements which draw their signification from the ensemble that they compose.

Hence, the deeds and the gestures perceived on the screen assume meaning or signification through the contexture of the film. Each event, each gesture or comportment, appears with a signification that comes to it, in addition to its own signification, from the relations that it entertains with everything that precedes and follows it.

But we should also point out that these significations are grasped from the start. Here, we come back to one of the major characteristics of perception: its immediacy. Perceiving, we noted at the beginning of this work, does 
not involve intelligently interpreting the world in order to reconstitute its meaning. Rather, it has a presence alongside the objects of the world.

And yet, by giving us events and gestures, the cinema is essentially addressed to this capacity for co-existing with things that is proper to perception in general.

It may be that the cinema is equally addressed to reflection, but this can only be a secondary aspect. As is the case with perception in general, the reflection that necessitates taking one's distance from the object can only be carried out after this immediate apprehension of the meaning of things, deeds, and gestures, which characterizes our first dealing with the filmic world and with the world tout court.

Let us summarize what we have said. The film, as a perceptual object, constitutes a 'gestalt' or a complex spatio-temporal structure in which the elements draw their meaning from their internal organization. These significations, which are significations of deeds and gestures, are initially grasped without the aid of the intelligence.

Now, we must say that if filmic comprehension - or, rather, filmic consciousness - borrows from perceptual consciousness its capacity for co-existing with things, it is nonetheless differentiated from it by many aspects. This is because the cinema is only a representation of the world. It does not give us the world, but only images of the world. And yet, if images of the real, like the real itself, offer themselves to us in the same manner as our unmediated sensations, they nonetheless solicit a different attitude.

Let us explain ourselves. Perceiving real behavior or perceiving represented behavior is, in both cases, grasping the meaning of this behavior. But what changes from one case to another is our manner of considering this behavior, of relating to it. In the case of visual representation, we know that the behavior under consideration, despite presenting all the characteristics of perception, is not physically present. Whence what we could provisionally call a vague sentiment of mingling two different registers: the real and the unreal. Whence also this behavioral difference when faced with an image or with reality. Many writers have tried to describe this intermediary position, specific to the cinema, between the real and the unreal.

Let us cite the titles of some very important articles in this respect: "Le cinéma entre l'imagination et la réalité" (François Ricci), ${ }^{20}$ "Limpression de réalité au cinéma" (Jean-Jacques Rinieri), ${ }^{21}$ "Le caractère de réalité des projections cinématographiques" (Albert Michotte van den Berck). ${ }^{22}$

Some writers believed that they were able to specify the nature of the real-unreal mixture on the basis of the objective characteristics of the 
image. The last article cited constitutes without doubt the most interesting attempt in this direction.

In order to orient this analysis, we can take this article as a point of departure.

\section{Film, Real, and Unreal}

Michotte begins with the following observation: the cinema gives a very vivid impression of reality, and yet, the reactions of spectators are very different from those of everyday life. They barely exceed the emotional stage. Does this mean that there are two different types of reality? This obliges us to distinguish between a belief in the reality of an object and the intuitive character of reality.

He states that "the movement perceived is real, and yet we know that nothing takes place on the screen apart from the rapid succession of immobile images." The conflict thus expressed is resolved, according to Michotte, by the introduction of the concept of 'illusion,' which is dedicated to the divorce between what we believe to be reality in itself and what merely seems to be real.

As Michotte writes:

This is an important distinction for the psychologist because in general, the reality of our beliefs rather than our intuition of the situation determines how we act. The cinema is again characteristic here, since our general attitude to film is that of a belief in unreality, despite the apparent reality of represented events, and this probably goes some way to explaining the difference in behavior just mentioned. But it would be wrong to imagine that this explanation completely resolves the issue. On the contrary, the psychological relation between belief and the impression of reality sets up for the cinema, and indeed for the theater, extremely tricky problems about which we know very little. For example, we must realize that the attitude of belief in the non-reality of perceived objects, permanent though it may potentially be, is neither constantly in operation nor ever able to be suppressed entirely by the impression of reality. Audience reactions to $3 \mathrm{D}$ cinema prove this when they are presented with a ball that looks as if it has been thrown into the auditorium. Even in conventional cinema, apparent reality cannot but impose itself in an absolute manner at certain moments. There are probably numerous oscillations of this kind over the course of a screening and what determines them should be investigated. ${ }^{23}$ 
This way of posing the problem is doubtless remarkable in many respects, even if, in our opinion, it is a little absurd to have apparent reality and a conviction of unreality co-exist in our consciousness. We will soon see that this mode of thinking likely derives from an effort to explain psychic realities on the basis of objective realities external to the spectator. Whatever the case may be, we will retain the following fundamental remarks for our reflection:

1. In real perception, there is a belief in the reality of the object, whereas in filmic perception, there is the appearance of reality and, at least potentially, the conviction of unreality;

2. Depending on whether there is belief or the impression of reality, our comportment takes on a different allure.

We now see how Michotte explains what he calls the "psychological relation between belief and the impression of reality." In his view, the method consists of "examining to what extent the laws known to govern perception allow us to theorize an impression of reality, and how such an impression differs from the one we assign to real things and events."

We can see that Michotte places his investigation on the terrain of objective realities. These are relations between the systems of excitation specific to everyday life and those governing filmic perception, which, according to him, impose on consciousness the impressions of reality and unreality.

He begins by examining the divergences between the systems of excitation envisaged. Let us briefly summarize them. Firstly, there are the changes in the setting that intervene in the cinema and remove from the perceived world the continuous character and phenomenal permanence that it possesses in real perception. Subsequently, there is the difference in the visual field: while the limits of the visual field in everyday life do not belong to the objects perceived (we always have the impression that space extends beyond what we can actually see), in the cinema, the visual field finds itself considerably reduced: the portion of space it encloses appears closed and strictly limited.

Analyzing the image in itself, we can observe that, as opposed to what happens in the real perceptual field, where the objects that we see are constituted by shadows, the realities that we project on the screen are patches of light, with the darker parts considered from the physical point of view as a sort of negative corresponding to the regions of the object that do not excite the retina.

Finally, one last divergence is the fact that the perception of shapes and sizes finds itself perceptibly altered in the cinema. The fact is that, due to 
its inability to reproduce the third dimension, the cinema does not entirely respect the principle of size consistency.

All these perceptual anomalies are, for Michotte, so many determinations of the impression of unreality. If it was necessary to focus on them alone, the cinema would be nothing but a set of a data imposing themselves on consciousness as unreal. But the film possesses other properties which, according to Michotte, perceptibly bring filmic data close to real data.

First of all, cinematic projection ordinarily allows us to see perspectival images. As Michotte explains:

The opposition between the moving figure and the still screen acts to segregate and liberate the object from the plane it had been in. The object somehow 'substantializes' itself and takes on an autonomous existence, becoming a 'physical thing.'

A second, powerful factor of reality is constituted by movement as such.

Finally, a third and final factor of reality would be the fact that the film, almost always, induces emotional reactions. For Michotte:

One final aspect of the question should be considered. Watching a film usually brings about numerous powerful emotional reactions in the audience and these obviously possess an immanent character of reality. $[\ldots]$ These emotions are intimately tied to what we see and above all to its apparent reality because it is not generally the image of the character which evokes our sympathy or admiration but rather what makes up their real personality, as constructed from their physiognomy and behaviour. Furthermore, there is empathy, that projection of our own emotions into the characters on the stage or screen which is well known to psychologists and aestheticians. Wouldn't all of this bring about a kind of return shock, a 'circular' process of reciprocal interaction, stronger than we might at first imagine, one which would confer a veritable resurgence of reality on people and the things they move around?

This last argument is differentiated from the others by the fact that it no longer exactly concerns objective realities. The views that it expresses are of a greater interest - this is, incidentally the reason for which we have reproduced this passage in its entirety - but we do not understand why Michotte introduced it into his reasoning. Emotion, in his view, is a tributary of the impression of reality, itself determined by objective properties. It could well be supposed that a circular process of emotion-empathy engenders 
a recrudescence of reality. But, in any case, in the final analysis, they are the only objective properties which, in Michotte's logic give the cinema its attribute of reality.

In any case, this is what transpires in his conclusions: "Now," he writes, "cinematic experience appears to be a peculiar conjunction of the 'real' and the 'artificial."

And what, for him, creates this 'peculiar conjunction' is none other than the conflict between a determined perceptual organization and our acquired experience, a conflict that is resolved through the impression of distance. As he points out:

We think, in short, that the cinematic situation may be described as one which makes us feel we are actually perceiving real beings and events, but that this reality is more or less distorted, since it belongs to a world which is psychologically speaking not exactly ours and from which we feel, in spite of everything, rather distant.

Michotte's analysis, as rich as it is in descriptive elements, nonetheless strikes us as rather dissatisfying in the explanations he gives.

His argumentation contains certain weaknesses that are necessary to analyze if we want to grasp the fundamentals of the film experience. First of all, if, as Michotte thinks, the impression of reality is a direct tributary of the relation between habitual perceptual elements and unusual perceptual elements, then we need to take into account the fact that, as a general rule, this relationship is rather constant. How can we thus explain these considerable variations of belief in reality which Michotte himself speaks about at the beginning of his article, of which a striking example is given to us by certain spectacular reactions during the very first film screenings? Indeed, if we are to believe film historians, these first representations sometimes engendered, among the spectators, manifest behavioral acts such as fleeing in terror.

Such behavior would be unthinkable today, and yet, the objective conditions of the representation of the real have been considerably ameliorated.

We can understand these facts if we admit that there is, in filmic consciousness, a certain knowledge: the spectators know that the reality unfolding on the screen is merely represented to them. And yet, this knowledge, well-structured today, was without doubt still ambiguous during the first film screenings. For the first fans of the cinématographe, who still had little familiarity with the screen, this knowledge was still too uncertain of itself to be effectively maintained in the unreal images whose apparent reality remained disarming for our minds. 
It could be objected that the knowledge of which we speak nonetheless stems from the objective conditions of representation, that it is the perceptual anomalies that engender the awareness of a certain unreality of the projected images. The schema proposed by Michotte would then remain entirely valid.

We should first note, however, that Michotte never refers to knowledge. He only mentions a conflict, and we are quite justified in thinking that this conflict is only exercised on the simple level of impressions. Consequently, is it certain that perceptual anomalies are the cause of the sentiment of unreality? If this were the case, many things would appear unreal to us. Let us take an example. Let us suppose a subject who is suddenly placed before an unpolished, misshapen pane of glass, behind which people move about. It is certain that the people perceived would appear to our subject as bizarre, because they would be particularly misshapen. But it would be no less true that they would remain just as real as they would be if they were seen in normal conditions.

Of course, our subject could, if they so desired, posit that these strange forms had come from some outlandish world. But this would necessitate an attitude of consciousness, an intention to interpret the shapes in question, since, in any case, the observing subject knows that they are real individuals actually existing in the real world.

Let us take another example, borrowed, this time, from the world of cinema. It happens that, during a film, in the middle of a succession of events unfolding in an apparently real world, a sequence appears to be thoroughly unreal. This is the case with sequences intended to represent the dreams (or daydreams) of characters in the film. It is also the case with animation films and films with fantastic settings.

How can we account for the two examples mentioned in the framework of Michotte's theory?

On the one hand, we have a very deformed vision, but posited as real without any equivocation, and on the other hand, we have a vision of an unreal world detaching itself from a world that is, in theory, midway between the real and unreal.

Can we still, after examining these two examples, affirm that what has been filmically perceived draws a certain unreal character from the objective deformations to which the representation of reality subjects it?

Such difficulties posed by Michotte's theory are surmounted if we make a distinction between unreality and absence. Unreality is what consciousness poses as being incapable of existence. Hence, the film experience, when the film limits itself to representing lifelike events, would not be capable 
of inducing an impression of unreality. By contrast, when the content of the film has, as its object, dreams or unrealistic events, the filmic consciousness evidently becomes an awareness of something unreal.

We can see that the qualities of the real and the unreal essentially depend on the manner in which we are given the content of the filmic representations, and bear no relation to the objective conditions of perception. There are some kinds of filmic content that solicit our consciousness to take them for reality, and others to take them for unreality, and the deformations of the perceived world are not responsible for any impression of unreality.

Let us now envisage the notions of absence and presence, and resurrect the example of perception through an unpolished, misshapen plane of glass. What radically distinguishes this example from the film experience is the fact that, although it is considerably deformed, the reality observed through the glass remains actually present.

The cinema, by contrast, only gives a reality that we know to be absent, or existing elsewhere, or not existing at all.

We touch, here, on a fundamental phenomenon. We can now see to what the knowledge we have just discussed refers. It is not, in the end, the knowledge of a certain unreality of the perceived world that is in question, but the knowledge possessed by the filmic consciousness that the reality it perceives, even though it has all the appearances of actual reality, is not present in its bodily physicality.

We can also see from where this impression of 'psychic distance' spoken of by Michotte stems. It cannot only be the consequence of a supposed mixture of the real and the artificial, since it is included in the filmic consciousness. The filmic consciousness indeed gives its object as not being there. So what would be so astonishing about the spectator feeling distant from the filmic world?

In fact, it now appears that Michotte has committed a double error. Firstly, by bringing together the impression of unreality and objective data, he ignores the fact that, in the final analysis, reality and unreality, absence and presence, essentially derive from knowledge, from a position of consciousness. Subsequently, he makes no distinction between unreality and absence.

Until now, we have been able to keep separate an essential aspect of filmic consciousness: it is a relationship with the world, but a world that is not present. Furthermore, this absence emerges from a position of consciousness.

And yet, the absence of the perceived world constitutes one of the essential characteristics of the imaging consciousness, such as it is described by Jean-Paul Sartre in The Imaginary. ${ }^{24}$ Thus, in order to discover more about the filmic consciousness, we must now try to situate our problematic in 
the general framework of the theory of the imaginary, such as it has been developed by the French philosopher.

\section{The Imaginary Consciousness}

Let us begin by offering a brief summary of Sartre's thinking. A quick overview of his reflections will help us to better pose our problems.

Reflecting on the imaginary consciousness, Sartre observes this supremely important fact: in all cases in which the imaging function of consciousness is active, it renders present an object that we know is not there. He writes:

The image is an act that aims in its corporeality at an absent or nonexistent object, through a physical or psychic content that is given not as itself but in the capacity of 'analogical representative' of the object aimed at. ${ }^{25}$

This phrase undoubtedly calls for some commentary.

With regard to the object targeted by the imaging consciousness, we can cite this interesting passage from The Imaginary:

To produce in me the image consciousness of Pierre is to make an intentional synthesis that gathers in itself a host of past moments, which assert the identity of Pierre across these diverse appearances and which give this same object under a certain aspect (in profile, in three-quarters, full size, head and shoulders, etc.) This aspect is necessarily an intuitive aspect: what my present intention aims at is Pierre in his corporeality, the Pierre that I can see, touch, hear, were I to see him, touch him, hear him. It is a body that is necessarily at a certain distance from mine, necessarily in a certain position in relation to me. Only, the Pierre that I could touch I posit at present as not being touched by me. My image of him is a certain manner of not touching him, not seeing him, a way he has of not being at such a distance, in such a position. The belief, in the image, posits the intuition, but does not posit Pierre. The characteristic of Pierre is not to be non-intuitive, as one might be tempted to believe, but to be 'intuitive-absent,' given as absent to intuition. In this sense, one can say that the image has wrapped within it a certain nothingness. Its object is not a simple portrait, it asserts itself: but in asserting itself it destroys itself. However lively, appealing, strong the image, it gives its object as not being. This does not preclude our then reacting to this image as if its object were present, before us: we will see that it can happen that we try, with all our being, to react to an image as if it were a perception. But the 
ambiguous and false state at which we thus arrive only throws into relief what has just been said: in vain we seek by our conduct towards the object to give rise to the belief that it really exists; we can ignore for a second, but cannot destroy the immediate consciousness of its nothingness. ${ }^{26}$

In any case, the imaging consciousness posits its object as not being present in its bodily physicality. But this 'positional act' of consciousness, as Sartre calls it, can take, in his view, four different forms.

The act can take four and only four forms: it can posit the object as nonexistent, or as absent, or as existing elsewhere; it can also 'neutralize' itself, which is to say not posit its object as existent. Two of these acts are negations; the fourth corresponds to a suspension or neutralization of the thesis. The third, which is positive, assumes an implicit negation of the natural and present existence of the object. These positional acts - this remark is crucial - are not superimposed on the image after it is constituted: the positional act is constitutive of the image consciousness... ${ }^{27}$

That is to say, the imaging consciousness includes, within its constitutive targeting of the imaginary object, the modality of existence according to which it is given as an object. This also implies that this modality of existence only depends on the imaging intention and not on the object imagined. We could, for example, neutralize the thesis - that is, not posit anything concerning the existence of the object - with respect to the image of a dragon or even view this dragon as being existent. Childhood consciousness, for example, views as existent beings (such as Father Christmas) which adult consciousness normally considers to be nonexistent.

But, if the imaging consciousness has as its essential and constant characteristic a positing of its object as not being present, there are other characteristics that can be modified and even disappear according to the objective matter on the basis of which the imaging function is exercised. In the case of the pure mental image - that is to say, when there is no material basis, beyond the fact that consciousness gives its object as non-present - it also appears as a creative spontaneity.

Let us return to Sartre:

A perceptual consciousness appears to itself as passive. On the other hand, an imaging consciousness gives itself to itself as an imaging consciousness, which is to say as a spontaneity that produces and conserves the object as imaged. ${ }^{28}$ 
Finally, we must still consider that, contrary to what takes place in perception, where we can observe and apprehend the object, in the mental image, the object is given en bloc, it is entirely determined, and nothing can let us know more about its nature.

Indeed, there is no sense in trying to enumerate the elements of an imaginary image. An image of this kind is what it is. We do not apprehend it - we constitute it.

As Sartre writes:

In a word, the object of perception constantly overflows consciousness; the object of an image is never anything more than the consciousness one has of it; it is defined by that consciousness: one can never learn from an image what one does not know already. ${ }^{29}$

In the intention produced by the absent or nonexistent object, there is a certain knowledge that is indissolubly linked with it, and which focuses on the determinations of the object.

In the case of the image that has a material existence, we can nonetheless note certain variations concerning the knowledge of the imaging consciousness.

Between the pure mental image and the portrait, the objective matter of the image is far richer and, correlatively, the knowledge about the object targeted evidently plays a less and less important role. Indeed, while in the case of the pure mental image, or in the case of the image created through a schematic drawing, or even more so in the case of the image created through an imitation, there is nothing in the image above and beyond what we put into it (the image is entirely penetrated with the knowledge we have of it), in the case of the portrait, for example, or the photograph, the rich, even perfect nature of the material basis of the image, its quasi-perfect resemblance with the intended object, does not solicit the intervention of knowledge to the same degree. Furthermore, we must also note that the portrait or the photograph can equally be an object of perceptual consciousness or of an imaginary consciousness.

The matter of a portrait is a quasi-face. No doubt it is first of all a neutral element that could just as well function as support for a perceptual consciousness as for an imaging consciousness. But this indifference is mainly theoretical. In fact, the spontaneity of consciousness is strongly solicited: these forms, these colors, strongly organized, almost impose themselves as an image of Pierre. If it takes my fancy to perceive them, 
they resist. A picture spontaneously offers itself in relief to the imaging consciousness, and the perceptual consciousness would have great difficulty seeing it as flat. This quasi-face, moreover, is accessible to observation: of course, I do not refer the new qualities that I see there to the object that I have before my eyes, to this painted canvas. I project them far beyond the picture, to the real Pierre. As a result, each judgment that I make is given as probable (whereas in genuine observation judgments are certain). When I say "Pierre has blue eyes," I imply: "At least, if the picture represents him faithfully.”

The matter of my image is a strictly individual object: this painting is unique in time and space. It should be added to this that the features of the quasi-face also have this inalienable individuality: that quasi-smile is the same as no other. However, this individuality appears only to perceptual consciousness. In passing from perception to image, the matter acquires a certain generality. We say: "Yes, it is just as he smiles," implying that the smile represents a mass of Pierre's individual smiles. We apprehend the different qualities of the matter as representatives that are valid for each of a mass of qualities that appear and disappear on Pierre: this pink color becomes the pink of his cheeks; this green gleam is the green of his eyes. What we seek through the picture is not Pierre such as he could have appeared to us the day before yesterday or on such-and-such a day of last year: it is Pierre in general, a prototype that acts as a thematic unity of all the individual appearances of Pierre..$^{30}$

Let us summarize. In the pure mental image where objective matter is lacking, the knowledge that we have of the intended object is alone responsible for the determinations of the object. Here, we have what Sartre calls the phenomenon of quasi-observation: we observe the mental image, but this observation teaches us nothing. In the case of the portrait, wherein the objective matter possesses an almost perfect resemblance with the intended object, such knowledge barely intervenes at all. Furthermore, the matter of the portrait can, at least theoretically, be the object of a perceptual consciousness or an imaging consciousness. In the end, the portrait is offered as a quasi-person accessible to observation.

It goes without saying that the elements that we have just recalled will be extremely useful for our own analysis. There is, however, one point that we would like to deepen, a point that has little importance in Sartre's theory, but which will have great significance on the problems occupying us. 
Regarding the portrait, Sartre's examples almost always related to an image representing an absent object, or an object existing elsewhere, but still having been the object of a pre-existing perception. The 'Pierre' of the portrait constitutes a concrete, known being for Sartre. With this in mind, Sartre passes quite rapidly over the phase preceding the appearance of the intention that constitutes matter into an image. He even seems to indicate that the observation of the quasi-face is still on the side of the perception ('seems,' that is, because at other moments the observation of the face constitutes an imaging consciousness for Sartre.)

Let us read these lines:

The matter of our image, when we look at a portrait, is not only that tangle of lines and colors that I just called it in the interest of simplicity. It is, actually, a quasi-person, with a quasi-face, etc. At the museum in Rouen, suddenly entering an unfamiliar room, I happened to take the people in a large picture for actual men. The illusion was of very short duration - a quarter of a second, perhaps - it remains nonetheless that I did not have, during this negligible lapse of time, an imaged consciousness, but on the contrary, a perceptual consciousness. [...] It is the case that, in the picture, there is the appearance of a man. If I approach it, the illusion disappears, but the cause of the illusion persists: the picture, made to resemble a human being, acts on me as would a man, whatever attitude of consciousness I took towards it in other respects. [...] The composure of this figure moves me directly whatever interpretation I may give it. In brief, these elements in themselves are neutral; they can enter into a synthesis of imagination or of perception. But although they are neutral, they are expressive. [...] The person in the painting solicits me gently to take him for a man. [...]

The portrait acts upon us - almost - like Pierre in person and, because of this fact, it solicits us to make the perceptual synthesis: Pierre of flesh and blood.

Presently my intention appears; I say: "This is the portrait of Pierre" or, more briefly: "This is Pierre." Then the portrait ceases to be an object, it functions as matter for an image. This invitation to perceive Pierre has not disappeared, but has entered into the imagined synthesis. ${ }^{31}$

We can see the difficulty that these lines contain. On the one hand, Sartre underscores the manifest difference between the appearance of a present 
object and the appearance of a quasi-face (the illusion was shortly lived...) and seems to indicate that this difference is that between perception and the imaginary ("I did not have, during this minute lapse of time, an imaged consciousness, but on the contrary, perceptual consciousness"). On the other hand, he suggests, at least implicitly, that the observation of the quasi-face remains on the side of normal perception by waiting for an intention to appear and be directed towards something other than the quasi-face, towards, that is, the real person. "Presently my intention appears... Then the portrait ceases to be an object, it functions as matter for an image."

Let us note here that criticizing Sartre's theory does not enter into our project. Doubtless, the difficulty that we raise is only a minor difficulty. But, by noting it and by trying to resolve it, we simply hope to be able to extract certain elements conducive to advancing our comprehension of our own problems.

How can we resolve this difficulty? Let us first interrogate its cause. It does seem that the ambiguity on which rests the perception of the quasiface derives from the fact that the example introduced by Sartre concerns the case in which the intention targets an already perceived object. The Pierre of the portrait is known elsewhere, and from the moment when the intention appears, it is brought towards someone whose existence is situated elsewhere. The matter of the portrait and the quasi-face then totally disappear from the background of the object targeted, of the true Pierre existing elsewhere, and are shifted, so to speak, to the side of perception.

And yet, if it is correct that the objective matter (forms, colors, etc.) of the portrait is indisputably situated on the specific terrain of normal perception, the apprehension of the quasi-face contains an element that radically differentiates it from perception, and which leads us to place it on the side of the imaginary, of non-presence.

Let us take an example. I have before me a photograph of a person I do not know, who I have never seen and, thus, who has never been the object of my perception. The person represented thus appears to me as a quasi-person with a quasi-face; he solicits me to take him for a real person, and I can observe him at leisure, as I would do of a true person, but the fact remains that I cannot see him, at any moment, as being present. There is, in the apprehension of the quasi-face of a photograph or a portrait, a positing of absence. The portrait or the photograph may well be lifelike and expressive, but I know that the person is merely represented, and I posit him as being non-present. It is simply that there is no positing of his existence, or, rather, there is a neutralization of the thesis as to his existence. 
Let us cite a passage from The Imaginary illustrating a case in which there is no positing of an existence:

If I look at the photos in a magazine, they can very well 'say nothing to me,' which is to say I look at them without positing their existence. Thus, the people whose photographs I see are indeed reached through these photographs, but without my positing their existence, just as the Knight and Death are reached through Dürer's engraving, but without my positing them..$^{2}$

We could also cite these lines from Husserl:

Let us suppose that we are observing Dürer's engraving, "The Knight, Death and the Devil."

We distinguish here in the first place the normal perception of which the correlate is the 'engraved print' as a thing, this print in the portfolio.

We distinguish in the second place the perceptive consciousness within which in the black lines of the picture there appear to us the small colorless figures, 'knight on horseback,' 'death,' and 'devil.' In aesthetic observation we do not consider these as the objects [Objekten]; we have our attention fixed on what is portrayed 'in the picture,' more precisely, on the 'depicted' realities, the knight of flesh and blood, and so forth. [...] This depicting picture-object stands before us neither as being nor as non-being, nor in any other positional modality; rather, we are aware of it as having its being, though only a quasi-being, in the neutrality-modification of Being. ${ }^{33}$

In short, to 'have' a quasi-person or a quasi-face indeed amounts to having an imagined consciousness, but one in which there is no positing of existence, and thus one in which the existential thesis is neutralized.

Now, it also seems that it is not enough to say that the observation of the quasi-face does not bear a positing of existence in order to exhaust its characteristics.

Rather, it must also be added that, in the case of the consciousness of the portrait, the neutralization of the thesis (that is, the absence of a positing of existence) is often conducted by an undecided consciousness, which has still not clearly established the existence of its object - or, in other words, of an imaging consciousness which has just emerged and still remains unfinished. The correlative of such a consciousness can only be a quasi-being. 
Or, to take another example: at the very moment in which a portrait appears to me (let us suppose it is life-sized in order to facilitate understanding), the person represented still finds himself at the edge of perception. He is almost a present person, and solicits our consciousness to make a perceptual synthesis. However, this absence is already included in the consciousness of the portrait and prevents it from being realized in the domain of perception. In short, we are in the presence of a form of consciousness that is still uncertain, an undecided attitude of consciousness floating between perception and the imaginary. On the one hand, although the quasi-face first appears absent, its resemblance with a face is such that I have a tendency to take it for a real, present face, presenting itself in a singular and unique attitude.

On the other hand, through its very absence, I have a tendency to take it as the matter of the image - that is, to target, through the portrait, a being existing elsewhere (or not existing at all), but which, due to this positing of its existence, would gain in generality, since each trait observed in the quasi-face is no longer valid for what it is in itself, but refers to a quantity of the traits of the person depicted in the portrait or the photograph.

We can now return to and clarify the genesis of the consciousness of the portrait.

In the first place, the portrait can be the object of a perceptual consciousness as much as of an imaging consciousness. We can, indeed, observe the colors and forms by themselves.

But the portrait, through its resemblance with a human face, barely permits the perceptual consciousness to be realized. In fact, we are immediately solicited to consider the person and the face, rather than the portrait as an object. At this stage, we have before us a quasi-person with a quasi-face. Resemblance can be such that we have a tendency to take the portrait for a real person.

The gaze of a portrait can sometimes be so lively that it happens that, at least for a brief instant, we have the sensation of being seen by a person in flesh and blood. And yet, in spite of the apparent reality of the object, there has already been a negation of the presence of the person. There is a quasi-person, that is, a quasi-presence, but we already vaguely know that this quasi-person is not there. At this point, the attitude of consciousness is still rather undecided. On the one hand, consciousness is already in the imaginary, in that it posits the non-presence of the object, and on the other hand, it remains on the side of perception through the tendency it has to take the portrait for a real person, quasi-present and fixed in a singular attitude.

But this relative instability of consciousness does not last for long. The awareness of the portrait as a portrait is soon made more explicit. The 
imaging intention appears more clearly and we tell ourselves: "that is a portrait." Thus, the portrait ceases to be ambiguous. Consciousness resolutely slides into the imaginary, and clearly poses its object as not being there. This does not mean, however, that there is already a positing of existence.

We know that a person existing beyond the painting is depicted, but we cannot posit anything about his existence.

In other words, the person is indeed targeted by the portrait, but without any positing of his existence from our part. It even happens that we let ourselves fall into the trap of resemblance, that we almost enjoy believing in the presence of the person. In any case, we still aim at nothing other than the singular aspect or the unique attitude that the person in the portrait presents. In short, at this moment, what we see in the portrait is not a person-in-general, but a fixed person with a particular attitude.

Now, should someone tell us that it is a portrait of such-and-such a person (a parent, perhaps), then there is a positing of existence. We posit the person as existing, or having existed, elsewhere.

Thus, consciousness ceases to adhere to the object in its singularity. The qualities perceived are projected beyond the painting, onto the real person of whose existence we are assured. We target a person-in-general, since each quality perceived in the portrait is valid for a quantity of others that we presume have appeared on the face of the person. We then say that the person has a friendly smile, or that he possesses a severe gaze, wishing to designate by this a smile in general or a gaze in general. But we must remark here that everything that we can say of the person-in-general, consists of presumptions on our part. Each individual trait of the portrait refers to a trait in general by the intervention of a sort of hypothesis on our part. It is actually given to us to see a unique attitude of the person in the portrait, and if the imaging consciousness is generalizing, it nonetheless remains connected only to the characteristics of the portrait, which remains in the foreground of our attention.

If, on the contrary, we find ourselves faced with the portrait of a person we know, then there is no presumption of a person-in-general, but rather recognition.

Our attention extends well beyond the portrait, to the multiple characteristics perceived in the real person.

Everything that we have known about the person flows from the face of the portrait whose singularity fades in favor of the generalities that become the center of our attention.

This final analysis of the consciousness of the portrait appears of interest due to the fact that the portrait, and the photograph, doubtless constitutes the matter of the image closest to the cinematic image. 
It is on this cinematic image that our attention will now be focused. It is now for us to ask how the imaging function is exercised in the specific case of the cinematic image. In other words, we must extract the specific structure of the filmic consciousness, with respect to all the other types of the imaging consciousness.

\section{The Attitudes of Filmic Consciousness Faced with Its Object}

In the first place, we can already affirm, recalling what we said about Michotte's descriptions, that filmic consciousness possesses at least one characteristic shared with all the other forms of the imaging consciousness: it posits its object as not being there. In other words, we know that filmic reality is not physically present and we posit it as such.

Once this point has been ascertained, we need to interrogate the different functions of the cinematic image, or, alternatively, the internal modifications of filmic consciousness.

Let us note that, for reasons which will come to light in the rest of this study, we will follow a procedure that is the inverse of that followed for the analysis of the consciousness of the portrait. We will begin with a case in which the object is existent and known (the home movie [ film-souvenir] ${ }^{34}$ in order to head towards the study of a case in which the object is unknown and non-existent (a fiction film) by passing through the intermediary case, in which the object is existent but unknown (a documentary film).

\section{a) The Home Movie}

It can happen that the cinema, like the portrait, offers to my vision images relating to a person who is known but absent or existing elsewhere. We can immediately see that this particular case of cinematic projection supposes a conscious attitude very different to that which engenders the fiction film.

Let us take an example: I want to recall the face or the whole physiognomy of a person I know. In order to do this, I can produce a mental image of this person, but I will only ever reach an imperfect representation. I can also take a photograph or a portrait of this person, and then I will find all the face's details. Photography, as we have seen, functions as an analogical representation of the absent person. But it lacks life. It gives all the characteristics of the face, but remains incapable of rendering expressions, looks, and familiar gestures which have been seen countless times on the person in question. If I desire to rediscover these known gestures, I can then, if I am an amateur filmmaker, project a film that represents the person in 
question, if they have been filmed on a certain occasion. The cinematic image, more than the portrait or the photograph, restores life. This time, I really do find the person.

In the three cases that we have evoked, the intention remains identical: every time, I render present to myself a person I know who is not there. In all three cases, there is a positing of existence. The person who I seek to render present to myself is posited as existing, or having existed, elsewhere. In all three cases, too, the goal is to find a person-in-general.

Thus, the matter of the home movie, like that of the portrait, acquires a certain generality. As for each of the gestures that I see on the screen, I do not apprehend them in their own individuality, but as representations of multiple gestures in reality. It matters little whether the person represented carries out a given particular activity. The activity in itself is of no interest. What interests me is to find, through the manner in which this particular activity is accomplished, a more general mode of behavior, repeatedly perceived in the absent person.

In short, what I seek to render present to myself is the person-in-general, such as I knew him in the multiple real perceptions that I have had of him. Thus, as in the case where I gave myself a known person through a portrait, our attention carries well beyond the cinematic image. The person-ingeneral, who is known in real perception, is the center of our attention. We can also say that, in the case of the home movie, the cinematic image truly plays the role of medium. It serves as an intermediary between the reality perceived and my current consciousness of this reality.

With the characteristics that we have just enumerated, we must still add that the consciousness of the home movie appears as a constitutive activity: it looks beyond the image, to the person-in-general that it depicts, in order to produce and maintain his existence even during the screening.

If this activity ceases, the person sought after gives way to an anonymous character on the screen carrying out equally anonymous and singular gestures, since they no longer refer to any general comportment.

Let us summarize. In the case of the home movie, there is, on the part of consciousness, a positing of existence, a generalization of the matter of the image that refers to a person-in-general, who constitutes the locus of our attention, and, finally, the creative activity.

\section{b) The Documentary Film}

We can now envisage the case of the documentary film, a case similar to the home movie in that it seeks to render present objects and people existing 
or having existed elsewhere, but which is nonetheless differentiated from the home movie due to the fact that (at least theoretically) the objects and people represented are not the object of any real perception.

Included in this category of films are biographical films - that is, documentaries on people. But fictionalized representations of the lives of historical celebrities (for instance, most films treating the Napoleonic era) are eliminated. These are hybrid productions halfway between fiction and reality, between myth and historical truth.

In order to facilitate our analysis, we will begin with a rather pure case of modest films - generally short or mid-length films - seeking to render, as faithfully as possible, individuals who are relatively little known to the public, or even completely unknown.

Cinéma-verité offers us some specimens of this type of film. We will find others still in certain works of new Canadian cinema (Lonely Boy, for example). 35

What takes place in these specific cases? As with the home movie, there is, of course, a positing of existence. We know that the person proposed by the film exists, or has existed, elsewhere, and we posit him as such.

As with the home movie, there is a certain generalization of the matter of the image. In other words, through the specific attitudes and comportments of the individual presented by the film, it is the general attitudes and comportments that the spectator considers, with the goal of rendering present the person-in-general who is the object of the film, and whom we know to exist elsewhere.

In the film Lonely Boy, for example, a film which seeks to give an overview of the life of the young Canadian singer Paul Anka, the behavior of the singer in question is not generally apprehended in its individuality, but as representative of a quantity of other types of behavior referring to the general comportment of the singer-in-general.

We should also note that in this type of film, the director usually chooses the most typical fragments of behavior, which are supposed to be the most representative of the mode of behavior of the filmed person.

Until now, the biographical film has not appeared any different from the home movie. In both cases, there is a positing of existence and the targeting of an object-in-general. For this reason, in both cases, there is a constitutive activity on the part of consciousness.

But we should also note that in this type of document, contrary to what occurs in the home movie, the knowledge about the person-in-general is contemporary to the viewing of the film. In the home movie, the image functions as a representative of a sum of real perceptions, which, in each of 
the specific appearances, flowed out of the person depicted. Thus, we have been able to say that our attention was focused on these real perceptions. The image, in other words, slid to the background of our attention and lost all singularity. Here, the process is quite different. We have not had any real perception of the character represented. We only have a vague idea of the character or no idea at all. Thus, if the perceived comportments gain in generality, or better, if they essentially serve as a representative for a general comportment, then it must be said that this generality is only acquired through a hypothesis or a series of presumptions whose point of departure can only be the particular behavior relayed by the film. No prior perception can precede the current filmic image, and this remains the center of attention.

We can illustrate this last affirmation by a new example.

With the goal of rendering present to myself a person who is a friend of mine, I have projected a home movie onto the screen. The first images present this person to me taking a cigarette and lighting it up. I perceive this unique gesture, but soon I also see something else: a familiar gesture that has really been perceived on the multiple occasions on which I have seen this friend light a cigarette. Or rather, the gesture in itself loses all signification, and I only retain fragments of particularly representative gestures of a general behavioral style that I have had the opportunity to perceive when faced with the multiple and diverse actions made by my friend. The cinematic image is filled with earlier perceptions. Its effective content ceases to be apprehended for itself. It is dissolved, so to speak, in the multiple real perceptions which it calls to my mind, and which flow into the structural elements of the behavior presently perceived. It is not my friend lighting a cigarette that I see, but my friend-in-general, such as he appeared to me through the multiple gestures of his which I have perceived, and which constitute the focus of my current attention. Now, let us suppose that another person watches this home movie at the same time as me. As he does not know my friend, this person finds himself in the same condition as the spectators of a documentary or biographical film. I tell him that the person on the screen is one of my friends. At this point, for this casual viewer, the individual on the screen is posited as existent. What is more, there is a search, by both him and by myself, for a being-in-general, and the matter of the image acquires a certain generality. But, for the other viewer, the cinematic image constitutes the only point of reference for this search for the person-in-general. Through the representation of my friend lighting his cigarette, this viewer aims for a structure of the entirety of his comportment, but this structure is simply presumed, and his attention continues to adhere to the cinematic image in its singularity. Whereas for 
me, there is a certain knowledge about my friend, which constitutes the pole of attention, and which flows into the image, for the casual viewer, there is the trace outline of a general knowledge about the film character on the basis of the particular characteristics of the images, which remain at the center of attention.

We can see, by passing from the home movie to the biographical film, that the cinematic image gains in autonomy with respect to the level of real perception. It further polarizes our attention, but nonetheless remains situated (as an intermediary) with respect to an unknown reality, posited as existing elsewhere.

Let it be noted that what we have just said applies to the documentary in general. It suffices to replace the film character by a group of individuals. The majority of documentaries indeed seek to take stock of the activities or the history of a defined social group (a working group, a sports group, etc.), or of a collectivity. In these cases, as in the biographical film depicting a single individual, there is a positing of existence (we pose the group as existing, or having existed, elsewhere), a generalization of the matter of the image (the group-in-general, its general style of activity, is targeted), a constitutive activity and a fixing of the attention on the image as a point of departure for the trace outline of a general knowledge.

We can now move on to a study of fiction film. As we will see, this last category of film (the largest) solicits, on the part of consciousness, a different attitude, in many aspects, from that which it adopts with respect to the home movie or the biographical film.

\section{c) The Fiction Film}

Let us envisage the case of the film relating an invented story - this case is all the more important in that it concerns the majority of film production - and refer once again to the same experiment.

This time, the images do not refer to anything existing. The characters who perform the action are indeed attained - it is perfectly evident that it is not the image in its objective reality that I see - but I do not posit that they exist (or have existed) elsewhere, and, moreover, I do not posit their non-existence, at least in the majority of cases. Rather, I am faced with a world of quasi-people, totally independent of the world known through real perception. We can thus say that, in the fiction film, the imaginary closes in on itself in some way: the characters seen are indeed posited as being absent, or rather, as not being there in their concrete bodily existence, but their physical appearance and actions do not refer to anything really 
existent, the filmic world is cut off from the world existing in perception in order to erect itself in an autonomous reality.

It follows that our attention is entirely centered on the screen. It also follows that the matter of the image no longer acquires any generality, but on the contrary, it is apprehended in all its singularity. In other words, the image no longer serves as a medium between a perception and a person-in-general or a group-in-general, it ceases to be valid as a representative sign of a larger signified, and solicits our consciousness to take it in its individuality.

This last remark already anticipates a modification in the form of consciousness's activity. In the home movie and the documentary film, we have been able to extract a certain constitutive activity that seeks and maintains the existence of the object-in-general that it targets.

This is not entirely the case in the fiction film. Here, the consciousness of the fiction film appears more passive, in the sense that it submits more to the object that it targets in its individuality, and that it follows in its particular evolutions. If there is activity, it is doubtless situated more at the level of retention, which integrates past events into present action (and of protention, which prolongs present action into the future), than at the level of the constitution of the object.

But we will have the opportunity to deepen this point when we study the function of movement more particularly. Before this, there remain several important remarks to make. First of all, if the fiction film no longer has any relation with existing reality, what is its status for consciousness? In other words, if the fictional world is purely imaginary, how should we characterize the degree of consciousness's belief in this imaginary world?

Let us examine our attitude when faced with the fiction film, and compare it with what we adopt in normal perception, and then, when faced with the documentary film.

In perception, we do not have to believe what we see. The perceived world initially gives itself as real. Sartre explained this well in the following lines:

When I perceive a table, I do not believe in the existence of that table. I have no need of belief, since the table is there in person. There is no supplementary act by which, in addition to perceiving that table, I confer a believed or believable existence on it. In the very act of perception, the table is discovered, disclosed, given to me. [...] The evidence peculiar to perception is therefore in no way a subjective impression that would be assimilable to a specification of belief: evidence is the presence for the consciousness of the object in person; it is the 'fulfillment' of the intention. [...] An evidence is a presence. Where evidence is given, belief is neither useful nor even possible. ${ }^{6}$ 
In perception, therefore, the objects are not 'believed,' but are immediately apprehended as existent.

In the documentary, or, more generally, in the case in which an existent object is targeted through an analogical representation (photography, film, etc.), the object is evidently not present to our intuition, but we know that it exists, and it is, in any case, its concrete existence that we try to attain through the image. Regardless of whether or not we have actually felt this existence, we posit it. In other terms, the awareness of the documentary is not disconnected from the real. It is simply their relationship that has changed. From now on, no more than for perception, we cannot say that the objects are 'believed.' They do not depart from the category of the real, and we apprehend them as real objects.

On the contrary, the objects, characters, and events of the fiction are not posited as existing in reality. They form part of an unreal world, the closed world of the film, which has no more relation with reality. It can, of course, be objected that a given object that appears in a film (an item of furniture, for example) really does exist, and that the spectator can, if they so wish, set their sights on this existence. But we must then note that the object, while recovering its place in the category of the real, ceases to belong to the world of the film. It is entirely one or the other. Either we think of the object in its reality, and consider it to be a studio prop, or we think of it in relation to the events of the film, and it appears as an unreal object in an unreal world. The same, obviously, applies to the characters of the film. Either we consider the actor and we are in the category of the real, or we consider the character and we are in the category of the unreal.

But if the objects, characters, and events of the fiction film are not posited as existing - that is, if they are not immediately apprehended as being real - we must still admit that they are 'believed.' The spectator believes in the unreal, and is fascinated by it. This phenomenon of belief that we find each time we let ourselves be 'taken away' by a fictional story has been characterized by Sartre, with respect to a problem close to our own: reading. Take this passage:

Reading is a kind of fascination, and when I read a detective story I believe in what I read. But this does not signify in the least that I cease to hold the detective's adventures to be imaginary. Simply, an entire world appears to me as imaged through the lines of the book [...] and this world encloses my consciousness, I cannot disengage, I am fascinated by it. This is the kind of fascination without positing existence that I call belief. ${ }^{37}$ 


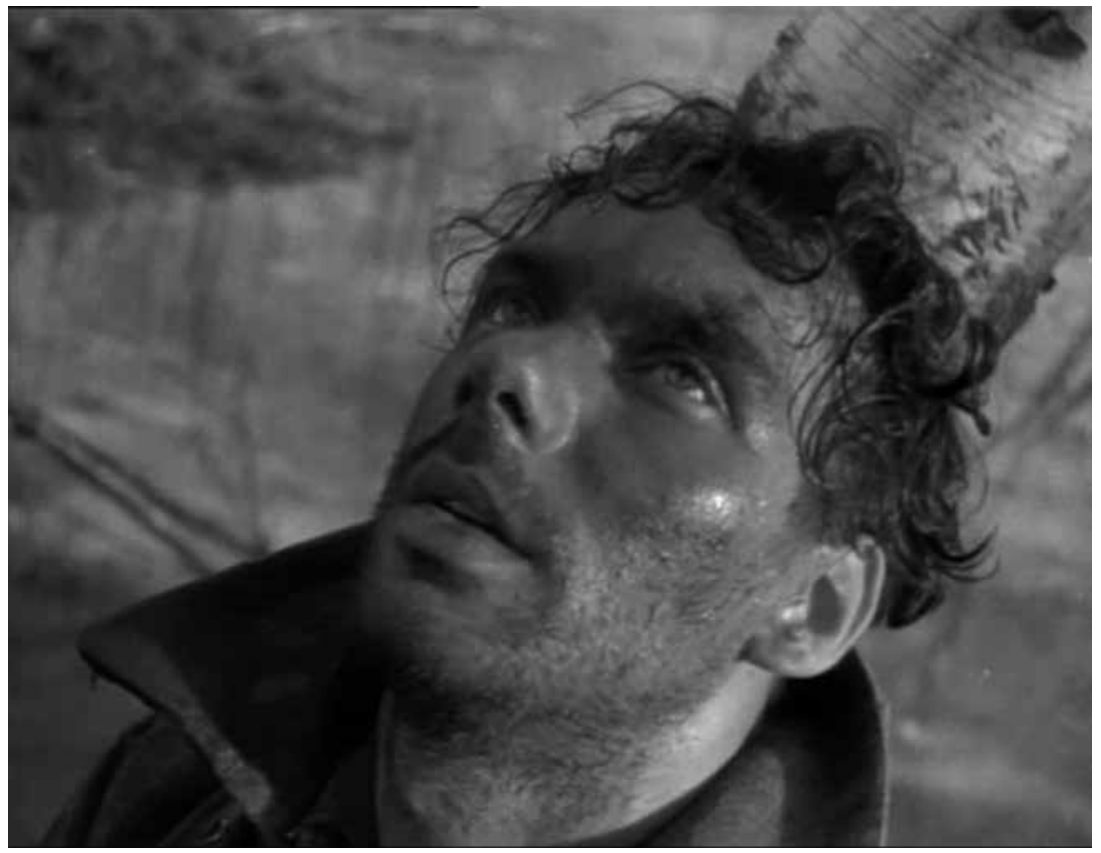

Fig. 4: The unexpected death of Boris (Aleksey Batalov) in Mikhail Kalatozov's The Cranes Are Flying.

What is true for reading is even more so for the cinema, since the latter, rather than offering us signs on the basis of which we 'imagine' an unreal world, directly gives us this unreal world in images, with an appearance of reality which, even though we are never deceived (when reading and when watching films, we never cease regarding the adventures as imaginary), solicits belief and fascination to a very high degree. We can better understand the phenomenon of fascination if we take note of the cases wherein the spectators, by themselves, break their belief in the adventure and the heroes of the film.

These breaks sometimes happen when the events presented by the film become unbearable, or when the hero finds himself in an excessively awful situation. In order to escape the unpleasant feeling instilled by a belief in the film, the spectator says, "It's just a film," thereby refusing to believe in the story unfolding on the screen.

To be more precise, let us examine a concrete example of this break. In doing so, we can shed more light on the nature of the phenomenon of belief.

On the screen, the young hero of Letyat zhuravli (The Cranes Are Flying, 1957) by Mikhail Kalatozov is mortally wounded, and his tragic end is described with such dramatic intensity that the scene becomes too awful 
for me to continue consenting to it. I tear myself away from my fascination and say: "It's just a film."

From this point, I leave behind the 'believed' world of the screen and return to my real situation as a spectator among other spectators, following an imaginary adventure. In other terms, I re-enter the category of the real, which I had momentarily evaded in order to consent to the unreal. The filmic world loses its density, it annihilates itself: for a moment, I have ceased to believe in it. This is not an act of denial. We do not deny that which is imaginary. We either consent to it or we do not. In order to deny an object or an event, the object or event must impose itself as such, as occurs in perception.

In the example given, I do not deny that the hero has died - this act of denial can take place, in a real situation, before a real death that I do not want to accept - but rather, I cease to consent to the imaginary world, I withdraw from it, as it were, in order to recuperate my function of the real and to enable me to consider the death of the hero as an unreal event. I acquire a certain distance with respect to this fact, which now merely appears to me as a product of the imagination, a shadow without any substance. In short, I stop believing in the imaginary world.

We can now see more precisely what belief is. It implies that we depart from the category of the real, in order to be fascinated by an unreal world, a world that we posit as neither existent nor nonexistent, that we never cease to regard as imaginary, but to which we consent, or rather, which we let ourselves believe in. Belief, in the cinema, is rather comparable to belief when playing. The child who plays 'cowboys and Indians' never ceases to regard his behavior as imaginary, but this does not negate the fact that during the game - that is, until the moment when he decides to stop playing - the child 'believes' that he is a 'cowboy' and 'believes' that his fellow players are 'Indians.' He is fascinated by the unreal world created by the game, just as the spectator is fascinated by the unreal world of the screen. Both act 'as if' the unreal were real. In other terms, they confer a 'believed' existence on objects that they never cease to regard as imaginary.

Such is the status of objects in a fiction film.

A second important remark concerns those cases in which, contrary to what we said above, certain characters are apprehended, not in their singularity, but as representatives of people-in-general, or, rather, charactersin-general. The popularity of certain actors is often the cause of such phenomena, above all when these actors remain confined to playing a specific type of character. James Dean, Jean Gabin, Sean Connery (as James Bond), and Fernandel are just a few examples of actors who generally restrict 


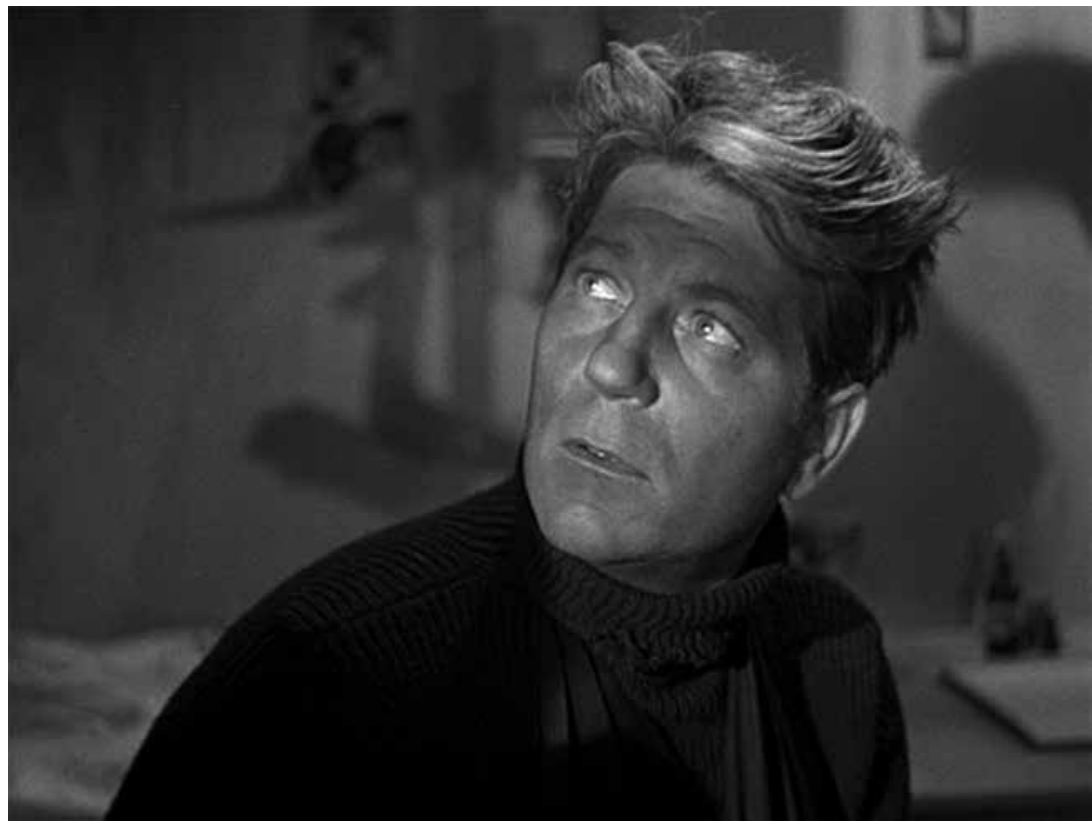

Fig. 5: Jean Gabin as the Lieutenant Maréchal in Jean Renoir's Grand Illusion.

themselves to certain roles. Let us suppose a fiction film in which the central character is played by a popular actor who generally appears as the same kind of character: for example, Jean Gabin. It then happens that our attention is diverted from the meaning of the specific action of the character, and focuses instead on the image of the actor's broader personality. We then say "that's Jean Gabin all right" or "that sure is how he acts," and we thus consider, via the present character he is playing, a certain general personality that we have seen in numerous other films. When such phenomena arise, we can see that the fiction film distinctly plays the same role as the home movie.

But it is important to note two things. Firstly, these phenomena are generally short-lived. The fiction soon takes over again and we forget Jean Gabin, in favor of the police detective or the businessman he is incarnating. Secondly, if such generalizations about the perceived being occur, and even present themselves frequently, it is essential that the character-in-general that we perceive does not leave the filmic world. Thus, in our example, we obviously do not seek Jean Gabin such as he is presented in real perception, but a certain film personality recognized in multiple films. Or rather, if it is true that our attention has been detached for a short moment from the specific character incarnated by Jean Gabin in order to focus on Jean Gabin in general, then this process in our consciousness paradoxically leads to 
a growing focus on the particular action of the character played by Jean Gabin. Indeed, at the same time as we think of Jean Gabin's specific film personality, there often forms within us a disposition to find and follow this same personality in his actions, once again incarnated in a singular character and action. The difference with the home movie is easy to discern. In the latter, the image essentially served as a medium, and its particularities fused into the ensemble of the characteristics of the person-in-general regarded by us, whose reality is located elsewhere. Here, the reality that we regard is not the Jean Gabin of real perception - there is no attempt to render Jean Gabin present as such - but a film personality, a manner of being known only in the filmic world, of which we expect a new manifestation in this same filmic world.

Another important remark concerns the modifications internal to the attitude taken when faced with a fiction film, modifications which derive from certain relations that the fiction has with the real.

We have said that, in the case of the fiction film, the image does not refer to any thing that exists or has existed elsewhere. And yet, there is a nuance to add to this proposition, a nuance that may be suggested to us by the expressions of certain spectators frequently heard when they leave the cinema, the object of which is to underscore the 'truthful' character of certain films. We say, for example, "that sure is how things happen," etc. The reason for this is that the fiction often maintains closer relations with the real than might seem to be the case at first sight. If we wish to be complete, it would be apt to study the changes in attitude that this implies.

Let us first distinguish between the purely fictional film, such as we find in heroic and fantasy genres, and this other category of films closer to the real, whose action unfolds, as Cohen-Séat has explained, at the level of the 'resembling-ego' [semble-moi].

In the heroic film or the fantasy film, there is, of course, no search for a reality existing elsewhere. The filmic world is perfectly autonomous since it is totally independent of all perceived reality. Sometimes, even, the lack of any verisimilitude in the story is such that it clearly solicits a positing of its non-existence. The characters we see are indeed perceived through the image, and we do indeed continue to follow them in their actions, but we do not think that they exist, or rather, we do not think that they can exist, which further seals the divorce between the filmic world and the real world.

In the second category of films, wherein the action unfolds at the level of the 'resembling-ego,' the story told - while often banal or representing familiar events from daily life - has the particular quality that it is lifelike, 
or at least possible. The action it recounts often refers to slices of lived experience, and the human conflicts and problems it illustrates can, to varying degrees and in various forms, be found in the common lot of mortals. This type of film is perceptibly close to the documentary genre - think of Italian neorealist cinema, for example - but is distinguished by the fact that it does not convey, beyond the image, a specific, existent, concrete reality. We can choose an example of a realist film that approaches the limits of the documentary: Vittorio de Sica's Ladri di biciclette (Bicycle Thieves, 1948). This film is presented almost as a social observation; beyond the characters it depicts, it invites us to consider a certain social reality. The film, therefore, refers to something other than itself, a specific reality existing elsewhere. But, contrary to what takes place in the documentary, this reality remains indistinct, vague, and undifferentiated. Thus, the bicycle thief is not posited as existing in his specific reality, that is as a personal being, but he is valid as a representative of a number of anonymous beings existing in a certain period and sharing the same problems with him.

What should we make of this?

As in the pure fiction, our attention remains fixed on the particular behavior of the character in particular, since this behavior is valid for itself. Indeed, we do not search for a certain general personality of the bicycle thief in the image, in the same way that we searched for a being-in-general beyond the behavior of Paul Anka in Lonely Boy, which, in any case, we posited as existent. Here, the behavior is not generalized, and is followed for itself. But, from the fact that it is inspired by existing events, it is, in a certain manner, impregnated with reality. The bicycle thief as such does not exist, but the existing reality that it illustrates confers on it a power of existence that gives it a certain substance of reality.

We should shed more light on this 'substance of reality.' We have seen that, in the fiction film, we confer on the objects and characters a 'believed' and 'credible' existence. The bicycle thief, as a fictional character, receives this 'believed' existence, and I may, if I wish to (or if I feel too uncomfortable with the situation he experiences), break my belief in him just as easily as I can break my belief in James Bond, or the hero in L'Homme de Rio (That Man from Rio, Philippe de Broca, 1964).

But if I do this, contrary to what takes place with James Bond or the 'Man from Rio,' there remains a residue of authenticity in the character that I cannot eliminate: the real man, or, rather, the possible real man, who is hidden behind the bicycle thief, and who I know exists in the anonymity of a certain social layer in postwar Italy. All of a sudden, at the same time 
as I break my belief in the bicycle thief as a fictional character, I must also, in order for this act to be complete, deny a certain social reality that this fictional character illustrates, and whose major characteristics he reproduces.

We can now see better what is meant by 'substance of reality'. It derives from the fact that a character, because he is the reflection of a certain category of real people, acquires this potential existence that the authentic quality confers on him.

\section{From the Home Movie to the Fiction Film}

There still remains for us to apprehend the film experience, but, before going further, it will be useful to briefly summarize the few conclusions that our thinking has provided us with.

In all the cases we have examined, we have been able to recognize this characteristic common to all types of filmic attitude: it is still a matter of being presented with an object that is not there, or that is not present in its corporal physicality. But if this characteristic has not changed, there are others which have been modified as a function of the knowledge that we have of what is represented, and correlatively, of the positing of existence that derives from it. Let us quickly refer to the different cases studied. From the home movie to the fiction film, via the documentary, we have seen that the existence of the intended object, posited and known in the first case, posited but unknown in the documentary, ceased to be posited in the fiction.

From one end to the other of this spectrum of possibilities, we have been able to note a progressive, increasingly structured adhesion of our attention to the reality on the screen, which was gradually constituted as a reality autonomous from the reality existing in perception.

At the same time, and corresponding with the increased attention given to the filmic object, the matter of this object ceases to be generalized. It even progressively ceases to be regarded as a more general object, and is instead increasingly considered for itself, in its individuality.

On the other hand, passing from the home movie and the documentary to the fiction film, we have also been able to discern a change in the mode of activity of the filmic consciousness. Beginning as a constitutive activity seeking a general, existing object, it then slides into a kind of submission when it is more attached to the particularities of the individual object that it targets and follows in the fictional world. 
Furthermore, we have also seen that, when passing to the category of the fiction film, the objects change their status for our consciousness: they are provided with a 'believed' existence, correlating with the act of belief that the fiction postulates.

Finally, even within the fiction, we have been able to highlight an important variation. In the pure fiction, above all the heroic film and the fantasy film, the filmic world is perfectly autonomous because it is totally independent of any perceived reality. In the realist fiction - whose content is inspired by existing reality or slices of lived experience - the behavior of the characters, even if they are fictional and thus individualized, also acquires a real substance through the power of existence that a certain existing, but general and undifferentiated, reality confers on them.

In conclusion, we should also note that the positing of existence does not essentially depend on the type of film. In the end, it is consciousness alone which is responsible for this positing of existence. It is quite evident that a home movie generally solicits a home-movie attitude, and that a fiction film demands that we comprehend it as a fiction, but this is not necessarily always the case. We can indeed posit a purely fictional character as existing, and we can also posit the Paul Anka of Lonely Boy as not existing.

In any case, it is probable that such phenomena take place and that the consciousness of the child can teach us a lot on this subject. But this is not our concern. We have only sought to determine certain general attitudes of filmic consciousness, particularly with respect to the evident manner in which each type of film solicits consciousness to comprehend it, outside of any deviation.

It is now important to shift our focus to an essential characteristic of the objective matter of the film: movement.

\section{Movement}

Up until now, everything that we have said about filmic consciousness has been said with respect to the different attitudes that consciousness can take towards the portrait or the photograph. The analogies are striking. We have above all highlighted the resemblances, on the one hand, between the portrait of a familiar person and the home movie, and, on the other hand, between the portrait of an unknown person and the documentary film.

We can even add another analogy, which we will not analyze, but which appears quite evident: that between the fiction film and the photo-novel or the comic book, which also show us invented stories. 
And yet, none of the types of photography envisaged possess this characteristic that is specific only to the cinema: movement. Moreover, none possess this power so often recognized in the cinema. It is this properly cinematic aspect that we are now going to look at. But if we do not wish to engage in empty discussion and lose ourselves in useless commentary on movement's power of attraction, we must first attempt a description of the perceptual experience of movement in order to highlight all the implications on the level of the attitudes of the filmic consciousness.

\section{The Experience of Movement}

The effectiveness of movement has often been underlined by numerous writers. The theories and descriptions of this are abundant, and we may, as a point of departure for our study, take a remarkable analysis by Wallon, which appeared in an article entitled "Lacte perceptif et le cinéma." 38

Wallon highlights two essential aspects of movement: its power of attraction and its power of life.

Let us cite the most significant passages:

From the point of view of perception, movement is also what happens first; we detach moving objects from their background, and detach from that the 'environment' in which this action occurs. The movement in itself has a power of effectivity.

Illustrating this 'power of effectivity,' Wallon evokes the example of onlookers whose gaze is attracted by the rapidly flashing letters of neon street signs.

Then, passing to the analysis of film movement, he adds:

In cinema there is something similar: we cannot take our eyes off the film whose images flash past one after another, because we would lose the thread of the story and would no longer understand what is going to follow, but also because as the images follow one another, there is a sort of attraction, a sort of induction working on us, on our attention, our senses, and our sight, to ensure that we retain everything. The movement is therefore something attractive and captivating in itself. I was telling you just now about the details in a film that attract our attention more by moving: that is the proof of this law of perception. You know that in order to discern extremely subtle things which wouldn't be visible if they were immobile, you give them some movement: in this way you manage to distinguish very slight tendencies, simply because of their movements. 
All these examples demonstrate something in movement that induces greater subtlety of perception and which stimulates the desire to perceive.

Finally, in addition to this power of attraction, and correlating with it, film movement, according to Wallon, possesses a veritable power of life:

But beyond this, movement possesses the power of life, a power of attraction which makes film subjugate our senses' ability to keep and attract this power, whereas in fact we are in an atmosphere completely foreign to the series of images passing before our eyes.

The power of attraction and the power of life: these are the two essential elements which, in Wallon's view, characterize film movement.

We will further see that these two 'powers' of movement function very differently according to the cases envisaged in the preceding section (the home movie, the documentary film, the fiction film). But first it would be best to analyze, in a deeper manner, the properties of movement such as they have been described by Wallon.

We should first try to illuminate the characteristics of movement in its most elementary nature - that is, the movement of a point.

Imagine an immobile point on a screen. This point, endowed with a certain luminosity, is clearly detached from the darker background. As such, it already has the power to solicit my attention. I can then fix my gaze on it and it will appear to me as a figure detached from a background, and one that maintains a series of fixed relations with the elements of the background, which entirely determine the position that it occupies. Imagine, for example, that the point is placed to the right, a little bit above the middle of the screen. But as such, and unless I willingly adopt an attitude of concerted observation, this inert and entirely determined point will be incapable of retaining my attention for any significant period of time. Now let us suppose that this point begins to move on a background that otherwise remains immobile. In this case, there is, in my visual field, the appearance of an overturning of the structure, in the sense that, losing its stability, the point constantly changes its relations with its surroundings. There is an indeterminacy of the object with respect to the background, which poses the problem of its destination, and orients in the observer an attitude of expectation. In principle, this attitude will only be relaxed when the object attains a new stable position.

Let us explain this matter in greater detail. When the object was immobile - that is, when it constituted, along with the background, a stable 
structure defined by a series of fixed relations - the act of perception was in a certain fashion completed once this ensemble of relations is perceived. I would naturally turn away from the object, and if, exceptionally, I had maintained my observational attitude, this could only be as an effect of my will, since nothing (or not much) in the object solicited my attention to further explore it. In other words, the immobile point, or, more generally, the immobile object, if it can momentarily attract our attention through its luminosity or some other characteristic, can only mobilize our gaze in a more prolonged manner through the intervention of our will deciding to further explore the structure of the perceived object. We should also note that this exploration is itself accomplished through a series of ocular movements (our gaze wanders around the object in order to deepen its relation with its surroundings), which are themselves accomplished in all directions, but following the manner in which I have decided to explore the object (from left to right, from top to bottom, etc.).

But when the object begins to move, when the stable relations it maintains with its surroundings are broken up, a new spatio-temporal structure appears. This is a structure that unfolds in time, whose starting point is well-known, but whose endpoint remains problematic.

And yet, it is the question of the becoming of the structure that solicits our consciousness and mobilizes our attention. There is an incomplete aspect in the perceived object, which induces an attitude of expectation based on the defined position of the observed point.

It is important to note that what consciousness focuses on is not the object as such, nor the different positions that this object can take when moving, but the whole structure that unfolds, the trajectory.

In this case, not only does movement mobilize the gaze through the question of its becoming, but it also implies that our attention is only detached from the object once the movement has been completed. Indeed, since consciousness focuses on the totality of the movement in progress, it must adhere to each particular position of the point as the only trace of its becoming. If it momentarily distances itself from the moving object, it loses the structure of the whole. Hence, consciousness must not be distracted. It attaches itself to each particular position of the point as the culmination of the movement that flows out of it, and that it retains, and also as the starting point of the future movement that it anticipates. With each position, there is an act of 'retention' and 'protention.' This absorptive, exclusive activity has no other goal than prefiguring what consciousness is focused on: the totality of movement.

With respect to a different problem than the one we are concerned with, Sartre, taking inspiration from Husserl, gave a very illuminating description 
of these acts of 'retention' and 'protention,' which constitute one of the essential aspects of the perception of movement.

He writes:

Husserl has given a remarkable description of these particular intentions which, starting from a living and concrete 'now,' are directed towards the immediate past to retain it and towards the future to grasp it. He calls these 'retentions' and 'protentions.' This retention, which itself alone constitutes the continuity, is not itself an image. It is an empty intention which is directed towards the phase of the movement that has just been annihilated; we say, in psychological language, that it is knowledge centered on the present visual sensation, and which makes appear that now as also being an after of a certain quality, an after that does not follow any sensation except precisely the one that has just vanished. The protention, on its part, is an expectation and this expectation gives the same sensation as also being a before. Naturally, this latter is not as strictly determined as a 'before' as it is as an 'after,' since [...] the sensation that will follow is not entirely known [connue]; but this sensation is already pretraced by a very precise expectation. [...] Retention and protention constitute, in every way, the sense of the present visual impression: without these synthetic acts, one could hardly speak of an impression at all; this before and this after that are correlates of these acts are not given as empty forms, as homogeneous and indifferent structures: they are the concrete and individual relations that the current sensations sustains with the concrete and individual impressions that have preceded it and that will follow it. ${ }^{39}$

A focus on the structure of the whole unfolding in time, an attention towards the indefinite becoming of the moving object, acts of 'retention' and 'protention' - these are the characteristics of the perception of movement, and we can now see what produces the 'power of attraction' of movement discussed by Wallon.

Whereas the observation of a static form (a form entirely determined in space and time) usually relates to a voluntary decision which is maintained for the duration of the observation, and which can be suspended at any moment without losing anything of the object (I can always come back to it), the observation of the temporal structure is solicited in a constant manner by questioning the becoming of the object, and can only be relinquished, in principle, at the end of the movement.

Correlatively, whereas consciousness, during the observation of the static object, is master of itself, of the points of view that it takes towards 
the object under consideration, and of the manner in which it decides to deepen a consideration of the qualities of the object, in the attention given to the dynamic object, consciousness is not in possession of itself to the same extent. It awaits the structure that is progressively discovered and that it therefore does not yet entirely possess. It is only when the movement is completed that it can recover itself and perhaps return to the attitude of voluntary observation of the perceived form that it then possesses in its totality, and that it can then represent to itself as a static ensemble: the trajectory or the totality of the path taken.

We can thus say that the perception of movement, or rather, the awareness of a form in becoming, is, owing to the fact that it is in the course of being realized and that it situates itself before its total completion, a pure expectation, or even an empty intention which expects to be filled by the object on which it is focused. In this sense, it must alienate itself in its attention to the various successive positions of the moving object, as the only traces of the global form that it contemplates. Such an attitude rules out taking any distance from the object. Our attention must coincide with each present position of the object insofar as this position is given as the culmination of the immediate past that it must retain, and as the starting point for the immediate future that it is projected to follow up to the conclusion of the spatio-temporal form in progress. We have thus been able to speak of a genuine 'attraction' of movement, a formula that is a little incorrect but highly suggestive.

Wallon has similarly spoken of a certain 'power of life' associated with movement. This second great characteristic of movement flows, according to Wallon, directly from the first characteristic, namely, the attraction exercised by movement. The two phenomena are doubtless correlative, but, in our opinion, what confers this power of life is the real or apparent autonomy of the moving object.

We should also note that when any moving object immediately appears not to be the cause of its own movement - for example, an object that I move about with my hands - it does not possess this power of life, and continues to appear to me as an inert object.

On the contrary, when an object moves inside my visual field, without an extrinsic cause for its mobility also appearing, this object appears to me as autonomous and draws from this autonomy its quality of a living being.

Let us return, for example, to the case of the luminous point moving on a screen. As long as this figure is immobile, it remains integrated with the background surrounding it as an inert object. But once the point moves, there is a segregation between the point and the background, and since nothing seems to give rise to this segregation, the point appears to us as 
being granted an autonomous being, and thus with life, because what we usually understand by the word 'life' is none other than this quality of being able to autonomously generate one's own movements.

There are plenty of other things to say on movement in general, and on its particular characteristics, but such a project would distance us too much from the subject at hand. We have, we believe, the essentials of the matter, and we can now focus on a study of movement in the cinema.

\section{Movement in the Cinema}

What we have just said about movement in general can also be applied directly to the cinema.

A film is, in fact, an extremely complex spatio-temporal structure, which presents us with action and behavior in becoming. Each shot is presented as a spatio-temporal structure integrated in broader structures, which we call sequences, and these sequences are integrated in turn into the whole spatio-temporal form constituted by the film.

On all levels (shot, sequence, film), the filmic consciousness awaits a becoming-in-progress, a total action that it considers in its entirety, and that it will only possess once the film is over. This is an empty intention which expects to be filled, and which must therefore adhere (and alienate itself in its attention) to the various successive moments of the film, in the sense that it must cling onto each one of these particular moments of the action, as the only visible points of the whole, and on the basis of which it can make its way towards the past or the future.

It is only when the film is over that consciousness can be distanced from it. At this point, it possesses the structure in its entirety, and can take a point of view on this structure. In fact, it can then be given or represented as a static form, because it is now conclusively finished.

To adopt a more figurative way of putting it, we could almost say that the filmic consciousness, during the screening, must coincide with or plunge itself into each present moment, as the only location from which it can perceive the moments that pass by and those that will follow. On the contrary, when the film is over, and consciousness possesses the whole, this whole can be given or represented 'from a distance,' as an object that it can handle, and on which it can take any point of view that it likes.

What we have just said about movement in the cinema is particularly applicable to fiction films, and we will later have the opportunity to return to this matter. First, however, it would be beneficial to quickly examine the role of movement in the other cases previously studied - namely, the home 
movie and the biographical or documentary film. This quick examination will not be useless: not only will it permit us to deepen the attitudes of our own consciousness in these two particular cases, but also, furthermore, it will allow us to better understand and explain the role of movement in the case of the fiction film.

\section{a) Movement in the Home Movie}

Here, as also, but to a lesser degree, in the documentary film, we will see that movement, by being subordinated to a specific attitude of consciousness, takes on a rather different signification from that which we have recognized on a general level.

Let us quickly recall what we said about what we can now call the homemovie attitude' [attitude-souvenir].

In this attitude, the intention is to render present a person who is not there, but who we posit as existing or having existed elsewhere. Since the goal is to rediscover the person-in-general, there is a generalization of the matter, in the sense that each gesture seen is not apprehended in its individuality, but as a representative of multiple gestures perceived countless times in reality. Moreover, our attention goes well beyond the image, extending to the real person we are focusing on, and, finally, there is a constitutive activity on the part of consciousness. In short, consciousness constantly exceeds the image, which serves precisely as a medium between the reality perceived in the past and my present consciousness of this reality.

In this perspective, therefore, the role of movement is largely reduced to being a factor of the liveliness of the represented reality. Indeed, the progressive becoming of the filmed action, or, more generally, the spatiotemporal form constituted by the entirety of the home movie, is of barely any interest to the spectator.

Hence, for example, if, in order to summon the memory of one of my friends, I screen a home movie representing various actions carried out by this person, the endpoint of these actions is of no interest to me. My intention is not to be given all of these actions in their entirety, but only to rediscover, in each shot, or in the various moments of the action in progress, familiar attitudes or gestures, specific to the person-in-general I am thinking of, and which have been perceived in reality on several occasions. In other words, each particular moment of the film is in some way isolated from the whole. The preceding moments do not interest me and I do not anticipate the following moments. Rather, each moment serves as the basis for the constitutive activity of consciousness to seek and find, beyond each specific 
image, the typical allures of a certain person-in-general who truly exists in reality. Unconcerned with the result of the actions it observes, consciousness is not an empty vessel waiting for reality to materialize. On the contrary, at every moment it is full of the object that it considers by means of the image, an object which appears to it in different aspects (my friend is walking, he is reading, etc.), but wherein each of these aspects contains the whole of the person (my friend has a certain way of walking, or reading, etc.).

We could almost say, in figurative terms, that the home movie gives rise to a longitudinal consciousness, which makes its way, via each present moment of the film, towards the real and distant object that it has in mind. On the contrary, when our mind focuses on a spatio-temporal structure in progress, consciousness is, in a way, 'lateral,' in the sense that it makes its way, via each present moment, towards both the past and the future. This is indeed what takes place in the fiction - but we will return to this point later.

Hence, in the home movie, movement is subordinated to the primary intention, which is to call to mind a real person existing elsewhere. Then, the total action that it sketches out is not (or almost not) taken into consideration, but, on the contrary, each present moment is forcefully detached to serve at each moment as a point of application for consciousness, which does not cease to regard a general, existing, and known object.

Our analysis, such as it has been expressed, is in all likelihood not entirely correct. Indeed, if we pushed our reasoning right to the end, we would end up claiming that our attention focuses on each specific moment, which would end up being isolated content pure and simple (that is, mere photographs).

And yet, in movement no present moment is ever given as an isolated content. It always appears as the succession of that which preceded it, and the starting point for what will follow it. In other words, each visual impression is always given as the basis of a retention and protention, which determine its place in the continuity of movement.

However, and this is important to note for the case that we are presently concerned with, retention and protention appear here as subordinated to the present moment, to the concrete, current impression on the basis of which I consider a general object.

Let us illustrate this last affirmation by returning to our example. In order to evoke the presence of one of my friends, I can try to imagine the person, but I will only end up with a very imperfect image. I can also take a photograph, and now the representation will be more convincing. If this photograph represents the person undertaking a certain action (for example, walking in the street), then I can seek and find, via this fixed representation, my friend's general mode of comportment. But this representation lacks 
life. So let us suppose that I possess a home movie representing this same person undertaking this same action. By following this action, which now unfolds in time and space, there are, of course, retentions and protentions that, at every point in time, give me the place of each present impression in the continuity of movement, but my attention, far from making its way towards the becoming of the observed act, or towards the past, as that which can illuminate the whole of the acts, is instead centered at every moment as the continually visible incarnation of a certain mode of comportment that I constantly call to mind in its generality.

We can see the difference between the photograph and the home movie: both restitute the specific mode of existing of the person considered, but, in addition to what the photograph provides, the home movie restitutes this mode of existing in action. The home movie shows us life, and we should also note that this characteristic has affective repercussions that are often more perceptible than those that are engendered by the fixed form of the photograph. To a far greater extent than the photo, the home movie, by means of the life that movement confers on it, is conducive to inducing a high degree of nostalgia, regret, or other sentiments in us.

We can also get a glimpse, here, of the difference between the home movie and the fiction film. In the latter, retention and protention, instead of accumulating in each present moment, project beyond the present moment, both towards the past and the future, in order for consciousness to take in the action in its entirety.

But, before elucidating this last point, it is apt to study in greater detail the intermediate case between the home movie and the fiction film, namely, the documentary film.

\section{b) Movement in the Documentary Film}

In the 'documentary attitude,' as we saw earlier, there is, as is the case with the home-movie attitude, a positing of existence, a generalizing of the matter of the image, a constituting activity, and a fixing of the attention on the image as a starting point for the sketch of a generalized knowledge.

When passing from the home movie to the documentary film, the cinematic image gains in autonomy as far as the level of real perception is concerned. It further centralizes our attention, but nonetheless remains situated (as an intermediate case) with respect to an unknown reality.

To say that the image further centralizes our attention already implies that movement takes on a different meaning from that which it assumes in the home movie. 
In the documentary film or the biographical film, all we know about the object under consideration is that it exists elsewhere, and nothing else.

Our intention is precisely to know more about it. Consequently, our attention is not focused only on each present moment, but on the ensemble of actions that are proposed to us. There is a knowledge that is formed by the projection, and that requires us to provide ourselves with a set of successively presented events. However, despite the fact that it comes very close to the signification that it takes in the fiction film, movement in the documentary film is distinct from it in several respects. These differences reside, we think, in the relationship that exists between retention and protention.

Let us take a concrete example.

Say I am watching a documentary film about a foreign country, and I am shown a group of indigenous people engaged in a typical activity, which, most of the time, has a symbolic, representative, and generalizing signification. Hence, if I am shown the indigenous people in question hunting or farming the land, I immediately know that I am seeing a people who are hunters or farmers.

Incidentally, the voice-over commentary is often there to confirm this generalizing opinion.

By means of each of these particular activities presented to me, I am always focused on a general style of existence. What is more, each particular activity brought to the screen gives me, in some sense, the totality of the object under consideration.

If I am shown the indigenous people hunting, farming, or devoting themselves to some other activity, it is always a general style of comporting themselves that I aim for, and that I attain through the multiple aspects given to me.

In short, in the documentary film, there is a knowledge that is formed on the occasion of each particular event, a knowledge that is constantly generalized and related to the reality that is aimed for.

Each particular shot appears as a particular perspective on a general comportment. That is to say that, in the documentary, movement does not engender this expectation of the future that we see in the fiction film. In general, we can cut the film after any sequence, or even right in the middle of a sequence, without the spectator being truly frustrated by it. This is because, at every moment, it possesses a general reality that presents itself on each occasion as a whole by means of the multiple, particular points of view given about it. No moment really summons any other moment. It is integrated with the preceding moments for the formation of an accumulating knowledge, but does not create any expectation of a future, because this 
future never appears as being truly necessary - at least before it appears - in order to illuminate the preceding moments.

Of course, one could reply to this that there exist all sorts of documentaries, and that certain among them come close to the fiction film, such that the attitude that we have just described finds itself modified to a great extent. Nanook of the North by Robert Flaherty (1922) is a good example of this.

Nanook, a real character chosen to illustrate the life of the inhabitants of the Arctic Circle, is indeed 'personalized' to the extent that we follow him more as an 'individual' than as a representative of a category of people, and that the 'becoming' of his actions has as much importance as those that precede them. When watching Nanook of the North, the attitude we take is almost the same as in the fiction film. But this is a particular case. On the other hand, since our project no longer involves describing the multiple variations and compromises within attitudes, but tries to describe rather pure types of these attitudes such as they are solicited by equally pure types of films, we will not dwell on marginal or ambiguous cases. These cases could, in any case, easily be understood on the basis of the major characteristics that the description of pure cases will have delivered us.

To conclude: in the case of the documentary or biographical film, there is firstly retention, in the sense that each present moment is integrated with past moments, while the whole constitutes itself into an additional knowledge on the object under consideration, and a generalization in the sense that, at any moment, the perceived object finds itself related to a general object that exists elsewhere.

In figurative terms, once more, we can see that the documentary gives rise to a consciousness that is both lateral - in the sense that, on the basis of each present moment, it makes its way towards the past in order to retain it and integrate it with the present - and longitudinal, in the sense that, on the basis of each present moment, it makes its way towards a general object that exists elsewhere.

In the documentary film, movement is what allows for a progressive, cumulative knowledge of an existing object. In this case, protention, or rather anticipation, is reduced.

\section{c) Movement in the Fiction Film}

Here, as we have seen earlier, there is no positing of existence. In a way, the imaginary is closed in on itself, in the sense that the filmic reality does not refer to any other existing reality. 
The filmic world is erected as an autonomous reality: there is no generalization of the matter of the image, which is apprehended in its singularity. Hence, our attention remains centered on the screen.

All this is to say that, in the case of the fiction film, movement ceases to subordinate itself to an intention that remains connected with existing reality.

On the contrary, it possesses the function that we recognized it had on a more general level. The film is presented as an autonomous spatio-temporal structure with respect to the reality of perception, and the intention is evidently to give oneself this structure in its totality.

The fiction film, therefore, creates an expectation, an empty intention that waits to be filled by the totality it takes into consideration.

The successive events are no longer a sum of independent points of view on an existing general object. Rather, they are linked in the whole structure that consciousness considers. Detached from existing reality, the only meaning they have is in relation to all the events that precede and follow them.

Consequently, retention and protention constitute the essence of consciousness's activity, which projects, beyond each present moment, towards the whole that is under consideration.

In other words, consciousness must dive into every present moment, as the only place from which it can perceive the past and project the future. In the figurative language we used earlier, we could say that the consciousness of the fiction film is a 'lateral' consciousness.

There follows a certain number of consequences, some of which will allow us to better understand the meaning of certain expressions currently utilized in filmological literature, which all underscore the hold exerted over us by the fiction film.

Thus, it now appears that the fiction film excludes almost any attitude of detachment.

In fact, in the other cases examined (the home movie, the biographical film, the documentary film), there remains a form of constituting activity on the part of consciousness which means that it remains the master of its object, from which it nonetheless keeps a certain distance. In other words, it is consciousness, in this case, which holds, 'at arm's length,' the general object that it projects at every moment on the basis of the individual events and characteristics that are given for it to see.

In the fiction film, by contrast, consciousness is constantly in an attitude of empty expectation that leads it to totally coincide with each present moment in order to lose nothing of the past or the future. Its project is, indeed, to possess the object it considers (the film in its entirety) and it 
can consequently take a step back once the action is over, that is, when it possesses, and can represent to itself at a distance and in its entirety, the total series of events represented on the screen.

This is doubtless one of the reasons for the 'fascinating' nature of the fiction film that has been so often noted by film specialists.

Let us note here that we prefer, instead of the term 'fascinating,' which we have reserved for the description of the phenomenon of belief, the term 'captivating,' which is more descriptive as it underscores the retention or 'capturing' of our attention by fictional events in their becoming.

If, to the preceding remarks, we can add the fact that the material conditions essentially aim to abolish the ambient reality in favor of the filmic reality alone (the darkened room, the comfort of the spectator, the big screen, the luminosity of the screen), then we have the essence of fictional filmic reality: an imaginary world (that is to say posited as non-present), which is autonomous, which imposes itself on consciousness by substituting itself for the real world, and which, thanks to its movement, solicits consciousness to coincide with it with barely any possibility of distanciation.

It is important to note here that, owing to the resources at its disposal, the cinema can on occasion provoke in the spectator a certain 'distanciation' with respect to filmic reality. The likes of Godard and Varda have honed a certain number of procedures aiming to break the spectator's enchantment, and to invite them to take their distances. But these are, when it comes down to it, rather artificial and rarely used procedures. The phenomena they provoke doubtless warrant a deeper description, but do not form part of our project, which, let us recall, is above all to highlight certain general types of attitudes.

We should also note that this 'captivating' character we have spoken about above is not found to the same degree in any other genre of fictional expression, such as the novel or, to take an example even closer to the fiction film, the photo-novel. We will now examine this latter case.

In the photo-novel, as in the cinema, a fictional story can very well engender in the reader a strong attitude of expectation for the becomingin-progress such as it unfolds by means of successive photographs. We will then see the reader excitedly leaf through the volume in a single sitting, even though the photo-novel is no more than an attempt to represent a story in motion that is artificially broken down into static fragments.

Contrary to what we can observe in the case of the film, however, there remain sequences of voluntary movements in the photo-novel, which prevent our total adherence to the story, or rather, a perfect coincidence with it. We must indeed pass from one image to another, turn the pages, etc., and what is more, we have, at every moment, the possibility of stopping and 
distancing ourselves from the passing sequences in order to envisage them in their entirety, while in no way losing anything of the future sequences.

In the cinema, by contrast, the spectators not only can but must submit to the unfolding of the story. They can never relieve themselves from their attention and can therefore only distance themselves from their object with much greater difficulty.

It follows that movement reinforces the autonomous nature of the fiction film we recognized earlier. Not allowing any withdrawal or relaxation of our attention, which must be focused on the succession of events, it impels a belief in the events and characters on-screen, even if this belief is brought into question once the film is over. Any relationship with reality is generally only considered afterwards. During the film, a belief in the specific reality of the film is customary, at least as far as the fiction film is concerned.

This last consideration leads us to formulate a very short and final remark on the differences between the filmic and theatrical situations. Although somewhat digressive, this remark will perhaps furnish us with a supplementary element for understanding the 'hold' a cinematic film has on us.

In the cinema, we said, belief is customary, a belief not in the authenticity or inauthenticity, or the existence or non-existence, of the object represented on-screen, but simply a belief in a quasi-world populated by quasi-presences which impose themselves on consciousness, and to which consciousness adheres without any detachment.

Theatrical scenes, by contrast, present events played by people present in their bodily physicality, but acting as analogical representatives of absent characters, who are posited as existing or having existed elsewhere (or even as not existing at all). In any case, we have in the theater the paradoxical situation wherein a physically present being stands in for a non-present character.

There ensues a certain segregation between a world of presences (the real people) and an absent but represented world.

Let us suppose, for example, a staging of Le Cid by Corneille. Rodrigue and the other characters are indeed attained via the actors, but we never lose sight of the fact that these characters are merely being played by actors. In fact, we are aware of an actor playing the role of Rodrigue. In other words, there is a certain constituting activity on the part of consciousness, which posits the fictional characters represented via the actors.

In the cinema, there is no segregation between the people who represent and the represented characters. There is not a world of fictional characters considered via a cast of present people. As a general rule, the fictional characters initially appear as fictional people in a fictional world. Hence, in Laurence Olivier's Hamlet [1948], Hamlet and the other characters are 
immediately registered as being fictional characters, posited as being nonpresent and evolving in a world equally non-present. Of course, we know the names of the actors, and certain acting personalities are sometimes so powerful that we cannot forget them (such as Orson Welles).

But it remains no less true that, in the majority of cases, filmic reality invites us to believe in the characters of the film without any distance, while in the theater a certain complaisance or disposition on the part of the spectator is necessary. We must 'play the game' and posit the fictional characters via the physically present actors.

In the theater, there is a constituting activity and the belief in the character is in some way feigned. The spectator remains in control, and is responsible for the belief in the characters, a belief that they 'play' under the effect of a sort of 'good will.'

In the theater, the spectator posits the fictional reality under consideration.

In the cinema, this reality directly imposes itself.

We can see that this direct, submissive adherence to the filmic reality has no equivalent in any other mode of expression. This is undoubtedly one of the most essential traits of the film experience.

\section{Conclusion}

To conclude this section is not merely, we should think, to summarize what has been said, but rather to take some distance, and cast a critical eye on the text and its contents. Any theory necessarily contains lacunae and imperfections which it is good to examine with an overriding concern for being constructive. This is what we wish to do here.

Let us first note that we are far from having exhausted the problem. This banal remark, which can be found at the end of every study as a necessary precaution, nonetheless here keeps its full meaning.

The attitudes that the filmic consciousness can take when faced with its object are indeed rather more diverse and complex than it seems upon reading our all-too-short analysis. We have indeed tried to specify three major types of attitude corresponding to three major categories of film, but it must be said that we have taken these attitudes in a pure state, such as they are solicited by equally pure cases of the home movie, the documentary film, or the fiction film. What is more, through a concern for the specification and the differentiation of attitudes, a concern that often thwarts the possibility of an exhaustive description of the multiple nuances which every phenomenon contains, we have doubtless framed or abusively crystallized each of these attitudes, thereby neglecting the subtle relations that they can have with 
the others, and the multiple intermediate modalities that scale from the pure 'home-movie attitude' to the pure 'fiction attitude.'

And yet, when looking closer, we can see that the attitudes described can succeed each other or intertwine with each other during the viewing of a single film, that a fiction film of a certain genre can solicit a home-movie attitude, or that a documentary film can be presented as fictional and engender a corresponding attitude.

Incidentally, it is important to note that the three attitudes described correspond to three possible positions that consciousness can take, and not necessarily to three objective categories of film. If it is true that the objective category of the 'fiction film' normally solicits a 'fiction attitude,' this in no way precludes the possibility of the 'home-movie attitude' or the 'documentary attitude' from appearing.

Whatever the case may be, by specifying three modalities of the 'filmic attitude,' we hope to have been able to furnish an adequate frame of reference, and, consequently, a verbal tool useful for the explanation of the nuances evoked above.

Finally, a second remark: we have also neglected those cases in which a voluntary, premeditated attitude gives a very special allure to the spectator's attitude. This is above all true for the fiction film. For example, it goes without saying that the critical attitude brings about a type of perception that is quite different to that of the naïve spectator. For the latter, we can observe this adherence without any distance, which we have spoken about at length. In the first case, a willed distanciation and a taking into consideration of the film as an aesthetic object thwarts this coincidence with the perceived object that the fiction film solicits, and brings about a more complex attitude whose description warrants its own chapter.

Finally, it goes without saying that the personality of the spectator and their particular interests can have a major influence, not on the type, but on the quality of the attitude taken. A film that is boring for one person because they see no interest in it will evidently not induce this intense expectation for the future that we have described as constituting the pure 'fiction attitude.'

In the same mode of thinking, certain technical procedures (or, more generally, the aesthetic aspect of the film) influence in their own way the type and the quality of the attitude taken. For example, we can think of certain successful suspense films whose technical qualities are all mobilized to engender, to a high degree, an expectation of the future and a passive and intense adherence to the perceived object.

In short, there exists a complex web of factors whose impact on the attitudes that the filmic consciousness can take is certainly not negligible, 
but whose detailed analysis would require at least one if not several volumes. Such a detailed analysis could not find any place in our own study, but it is necessary to signal its possibility, as well as the principal elements that it ought to envisage.

This said, it seems useful to summarize in a short synthesis the various aspects of the film experience that we have been able to unearth.

The filmic consciousness, we have seen, consists of a certain manner of referring to an object, a manner that is different from that which we encounter in real perception, and also different from that which defines the pure imaginary, but which nevertheless comes close to this last, in the sense that it targets an object not physically present, or, to adopt Sartre's language, an object that we posit as a nothingness [néant d'être].

The filmic consciousness is thus a relation to the world, but to a world posited as non-present.

Now, we have seen that the object of the filmic consciousness, an object always posited as non-present, can refer either to an existing and known object or an existing but unknown object, or indeed to nothing existing at all. In both of these different cases, the attitude of the filmic consciousness varies considerably. Correlatively, movement, an essential element of the filmic datum, has a diverse array of functions.

When the object is posited as existing or having existed elsewhere (which is generally the case for the home movie), there is a constituting activity on the part of consciousness, in the sense that, via the individual matter of the film, it seeks and finds the object-in-general which it knew, which exists elsewhere, and on which all its attention is focused.

Movement, in this case, has the essential function of giving life to the perceived object. Retention and protention appear as subordinated to the present impression, an impression which constantly serves as the basis for consciousness to seek out the general object known from elsewhere.

When the object is posited as existing but was not known in real perception (which is generally the case for documentary and biographical films), there is also a constituting activity on the part of consciousness, which constitutes a general object on the basis of the individual matter of the film. But since our knowledge of the object is contemporary with the screening of the film, our attention must be more attached to the image as a starting point for the sketch of a general knowledge.

Movement here has as its principal function the progressive unveiling of certain aspects of the object, necessary to the formation of an additional, generalizing knowledge. The activity of retention thus appears more important than the activity of protention. 
In one word, the activity of consciousness consists above all of retention - which makes it submit more to the filmic datum than it does in the home movie - and generalization, and it remains a constituting activity which keeps it distant from the filmic reality as such.

When there is no longer any positing of existence on the part of consciousness (this is generally the case for the fiction film), or, in other words, when the filmic reality no longer refers to anything existing in the real, and finds itself bestowed with a 'believed' existence correlative with an act of belief on the part of the subject spectator, there is of course no longer any generalizing activity. Our attention remains fixed on the perceived object in its individuality and must submit to it. The activity of consciousness is exclusively realized in retention and protention, which, this time, have the goal of integrating at every present moment the ensemble of past events, and projecting future events on the basis of these same moments.

Here, there is no longer any possibility of a detachment or a distanciation with respect to the filmic reality. The coincidence with the perceived object is customary, and this reinforces the autonomous character specific to the fiction film.

At the end of the day, it appears that our attitude towards the filmic reality is not only radically different from our attitude towards real (present) objects, but that it can also adopt very different forms according to the modalities of existence of the object under consideration.

By describing these variations in our attitude, we hope to have been able to explain some aspects of the film experience, but also, we believe that we have sketched out a useful framework for the study of our behavior when encountering a film.

To define certain types of attitudes according to their structure and their specific particularities was indeed necessary for the comprehension of filmic behavior, which necessarily draws its form from the attitudes that underpin it.

It is this behavior that we will now discuss.

\section{Chapter II: Filmic Behavior, Identification}

At the beginning of this study, we defined identification as a behavior of private intersubjectivity, understanding by this that it is a question of the comportment rooted in the terrain of anonymous intersubjectivity - a sort of generic coexistence of subjectivities - but subsequently structuring itself in a personal relationship, that is, in the behavior of private intersubjectivity. 
The analysis we have carried out on identification related principally to real situations in which the members of the relationship are both present to each other. Now, it is a question of examining how identification in a filmic situation is realized, that is, when one of the members of the relationship is presented as not being present.

There is no doubting that the essential structures of identification are not modified - in both filmic situations and real situations, we find the same postural apprehension of other people, as described earlier - and it would be wrong to make filmic identification a privileged form of behavior without any equivalent in real situations. Too many writers have begun with this false premise in order to then make our identification with a character (which also goes by the name of 'participation' or 'empathy') a unique mechanism, one that is comparable, as much on the level of its form as on the level of its possible influence, with an identification with certain particularly structuring forms of behavior such as parental identification or the phenomenon of identification in a psychoanalytic situation.

For us, there is no question of positing filmic identification from the start as a privileged form of behavior.

Following the principles that we have detailed at the beginning of this work, identification is a general mode of behavior that is traced out in every encounter, and that is structured according to different modalities depending on the type of relationship at issue.

In this conceptual framework, filmic identification is a variation of identification as a general mode of behavior, a particular type of identification corresponding to a particular type of relationship, one in which the object, although presenting almost all the characteristics that it possesses in perception, is presented as absent in its bodily physicality.

Provisionally leaving to one side the question of the choice of characters with whom the viewer identifies, and what determines this choice, we will now try to specify the major characteristics of this particular type of identification, filmic identification, while taking into account, of course, the internal modifications that it can undergo in line with the types of attitude that we were able to distinguish earlier.

\section{The Types of Filmic Identification}

\section{a) Identification in the 'Home-Movie Attitude'}

We know that, in the home-movie attitude, the image functions as a representative of a known but absent person, that the matter of the image is 
generalized, that there is a constituting activity on the part of consciousness and that, in the end, since our attention remains centered on the object existing elsewhere and known in real perception, it is not the series of events presented that is targeted but only each present moment.

All this leads us to presume a particular form of identification, a very special manner of entering into intersubjective relations with other people. In order to explicate this, we will once again refer to lived experience, and imagine a concrete example.

Say I project a home movie showing people I know in various activities.

At one point in the film, one of them appears to me in a close-up, smiling. I then happen to smile with him, or rather, like him - that is to say, I reproduce the smile that I apprehended in another person. We can recognize here the postural aspect of identification Hesnard spoke about, which, although it is manifest in our example, is customarily more silent and almost undetectable from the outside.

But we must note that here it is not the specific smile shown by the film that is the object of identification.

We know, in fact, that in the home-movie attitude, the acts perceived are not focused on for themselves, in their individuality, but as a representative of a certain general manner of acting such as it has been experienced through multiple real perceptions.

In the same manner, the acts 'reproduced' or 'mimed' by identification are not reproduced or mimed on an individual basis, but on a general level.

Thus, in the smile that I mimed upon seeing my friend smiling in the film, there was more than a simple reproduction of the individual act that has been perceived.

It did indeed involve miming a certain general manner of smiling apprehended through the specific smile shown in the film. In other words, the smile reproduced by identification constitutes a kind of synthesis of all the smiles apprehended on the occasion of numerous identifications in real situations.

There is an entire knowledge that is incorporated with the postural attitude of reproduction, a knowledge which bears on a behavior-in-general and which largely exceeds the individual act reproduced on the screen. These individual acts are, incidentally, only a means for the actualization of this knowledge. Hence, the smile that I saw on the screen was only, for me, the opportunity to remake the experience of a smile known for having been perceived and apprehended over the course of numerous circumstances.

We can already glimpse the meaning or the role of identification when it is developed within the home-movie attitude. 
But beforehand, let us look at the role it does not play.

Such an identification, it can be seen, is not a participation in the acts perceived on the screen. In order for this to be the case, these acts would have to be considered on an individual basis and thus perceived 'in situation.'

Let us explain this point further. If, for example, in a home movie, I perceive a friend running, it is not, of course, the act of running itself that I apprehend - the meaning, that is to say the origin and the goal of this act does not, in fact, interest me in the slightest - but rather, as we have seen, a certain general manner of running which itself reflects a general manner of acting which is that of my friend. It would be another thing entirely to see a character from a fiction film running. In this case, identification would indeed have the act itself as its object, in its individuality and with its meaning. This identification would then often assume the guise of a participation. If, for example, the running of the character in question has the meaning of an escape, then it is the comportment of escaping which we apprehend, and with which we identify, with all that this implies.

But this presents the opportunity of deepening the genre of identification when we study the fiction film more precisely.

The identification in the home-movie attitude is not a participatory behavior. Nor is it, however, understanding in the general sense of the term. There is, in fact, nothing to understand in the observed acts. In other terms, the identificatory behavior as applied to the home movie teaches us absolutely nothing about the person under consideration. On the contrary, as we clarified above, it is the actualization of a certain intuitive knowledge bearing on a general behavior which is formed on the terrain of real perception on the occasion of previous contacts.

But why is this actualization realized? What is its meaning?

In our opinion, it essentially involves a kind of 'incantatory' behavior intended to 'presentify' the person under consideration, and evoke their presence.

Let us explain this further. In the example given above, there was on the one hand my intention to render a friend present to myself, and on the other hand, a film sequence showing me this friend smiling. Since my attention does not focus on the individual smile on-screen, but on a certain mode of smiling specific to my friend who I know exists elsewhere, my postural attitude was fashioned as a function of what I know about the mode of smiling possessed by my friend-in-general who exists elsewhere.

It is therefore a matter of identifying with an absent person who is realized through the intermediary of the image, a vicarious identification. My goal was therefore to enter into intersubjective relations with an absent 
person through his image. Thus, the smile of the screen was given as the 'phantom' of my friend's real smile such as I have seen it in perception, such as it is presently realized elsewhere, and which I regard in its most essential aspects.

But to state that, in the case of the home movie, identification is a form of vicarious identification says much about the meaning of this behavior. This amounts to saying that we are dealing with an empty identification, a behavior that is realized as if the person under consideration were present in flesh and blood, and which even incorporates everything that it knows about the absent person, who is not directly perceptible on the image. This is a behavior that 'plays' the presence of the object. In short, it is an effort to apprehend a real but absent comportment which remains out of range. This is why we say that it is a kind of 'incantatory' behavior.

Incidentally, it may be apt to remark that the feelings accompanying this behavior are also sentiments that are 'played,' simulacra of feelings that could inspire in us the effective presence of the person under consideration. Hence, the sympathy felt for a 'presentified' friend in the home movie is evidently not inspired by what the screen shows us. It draws its origin from the real contacts that we have seen with the friend sought after. What is more, it is linked to the presence of this friend and, even when it functions for no purpose, as is the case with the image of my friend, it must also be interpreted as an attempt at 'presentification.' In fact, in order for these sentiments of sympathy that I feel for a determinate person to be produced, we must have the presence of this person or, absent this, a substitute for this presence. The cinematic image offers us this substitute and allows us to feel this sympathy linked to presence. At no moment do we lose sight of the fact that the image is only a substitute, a simulacrum of presence. And yet we continue to feel sympathy, even when it functions for no purpose. More precisely, we realize this sympathy within us in an effort to join the real person from whom we remain irremediably cut off. As we can see, the affective aspect and the postural aspect are merged in a single, unified behavior which is essentially defined as an effort to evoke the presence of the object under consideration. But we must also say that this behavior always fails. We 'play' at believing in this presence, but we never get there since we are always aware of the absence of the object.

We might even add that the more the characteristics of the substitute are close to the real characteristics of the object such as it can be perceived, the more the failure of our behavior is felt. We can, in fact, try to render a person present by different means. For example, we can produce a mental image, or utilize a photograph or home movie. In all three cases, the behavior has 
the same meaning. In all three cases, too, this behavior is doomed to failure, but we can observe that this failure is generally felt with more violence for the home movie than for the photograph, and with more violence for the photograph than for the mental image.

The fact is that, from the mental image to the film, the image gains in precision and vivacity. It thus becomes more apt to evoke the presence, and more apt to render the object such as it can be seen in perception. At the same time, and paradoxically, it expresses absence with much more clarity, quite simply because, by further resembling the real object, it lets us better take stock of what the effective presence of this real object would be. Consequently, this 'absenteeism' is all the more clearly felt, and the resulting disappointment is all the greater.

In the home-movie attitude, our behavior consists of a vain effort to 'presentify' the object, an attempt to enter into intersubjective relations with other people, which necessarily leads to disappointment.

All this leads us to make a final observation. At the same time as the absence of the object is felt, and correlatively with this fact, the presence of the spectator is experienced as useless, without any meaning. This is because, by wishing to render a person present, it is often our presence to the person that we try to evoke. In sum, we seek a relationship of real intersubjectivity. But, once the object is irremediably revealed to be out of our grasp, this will for a personal engagement in the relationship is experienced as being absurd.

It is confronted with the void, and remains suspended, without any possible outlet or any real signification.

To conclude: in the home-movie attitude, our own presence is constantly felt insofar as it is one of the poles of the relationship that we would like to see realized, and it is felt all the more for the fact that, since it is incapable of being engaged, it remains entirely preoccupied with itself.

This situation is comparable to the situation in which we have attempted to take hold of an object that is out of our grasp. Insofar as the object can be grasped, we simply have the awareness of an object to be held, and the gesture to take hold of it barely attracts our attention. By contrast, when it is out of our grasp, our attention focuses on these gestures. We are then aware of carrying out useless, symbolic gestures which embarrass us in their absurdity.

We could speak at much greater length on the behavior we have just studied. There would be a great deal of nuance to add, and numerous specific cases to examine. In any case, we believe we have touched on the essence of the structure and meaning of this behavior, an essence that we can summarize in the following terms. 
In its structure, identification in the home-movie attitude essentially consists of the actualization of an intuitive and synthetic knowledge of the object under consideration, an actualization which is realized thanks to the perception on the screen of behavior that is objectively individual but generalized by the spectator. In its meaning, this type of identification consists of a vain effort to evoke a presence that remains irremediably out of our grasp.

\section{b) Identification in the 'Documentary Attitude'}

In the documentary attitude there is, as we clarified in the preceding chapters, a positing of existence, a generalization of the matter of the image, a constituting activity and a fixing of the attention on the image as a starting point for the sketching of a general knowledge. In the end, the essential function of movement is to permit the formation of a progressive, cumulative knowledge in the object presented by the film. In this sense, the activity of consciousness consists, above all, of a retention and a generalization of the perceived object.

Within this attitude, how is identificatory behavior structured, and what is its meaning?

Let us first of all note that here the quality of identificatory behavior depends to a large extent on the interest felt by the spectator for the subject of the documentary. This remark is, incidentally, very general, and applies just as much to identification in the home-movie attitude as it does to identification in the fiction film. However, it is appropriate to formulate it in specific relation to the documentary film, since, in this case more than in the other two cases, our attention risks being distracted. This is because the documentary aims to procure a certain knowledge about a certain object, and if this object does not interest us, we will experience the film in a very distracted manner instead of following it attentively.

But since our project is to explain certain characteristic attitudes and forms of behavior, we envisage the case wherein the spectator is interested and follows the film attentively.

In order to orient our analysis, we will once again refer to a concrete example. Take one of the numerous documentaries about medicine. For example, take a documentary whose goal is to teach the spectator about the lifestyle of country doctors, and the difficulties they face. The film shows one of these medical practitioners in some of his most representative activities: talking with patients, taking their pulse, difficulties in moving around, emergency cases, etc. 
If I am interested, I will apply myself to the task of grasping the sense of this doctor's behavior by identifying with him. But here, as with that form of identification that develops within the home-movie attitude, his behavior is not apprehended on a strictly individual level. We know, in fact, that, in the documentary attitude, the perceived object is generalized, in the sense that it refers to a more general reality existing elsewhere. Thus, the particular manner that our country doctor has of conducting himself with a patient at a given moment in the film, presented as a general style of his comportment with his patients, proper to the real-life doctor and, through him, to country doctors in general. Consequently, what we try to apprehend through the individual behavior with which we identify is a general style of comportment, such as can be observed in numerous country doctors. We can see the difference with fiction. In a fiction film, the comportment of a doctor does not refer to anything existing. It would have no meaning with respect to existing general reality. Its only meaning relates to the story told by the film, an individual story made up of individual forms of behavior interacting with one another. This comportment would then be apprehended in its singularity.

Within the documentary attitude, identification therefore has a generalizing nature. It involves apprehending, on the basis of particular behavioral acts, typical or general modes of comportment.

But if this behavior is generalizing, it is not generalizing in the same manner as that which is developed in the home-movie attitude. In this case, there is a whole knowledge that incorporates the postural attitude of reproduction, a knowledge which is naturally intuitive and formed in the course of earlier perceptual acts.

Here, by contrast, knowledge is contemporaneous with viewing the film, and is formed precisely during the film screening.

Briefly put, in the documentary attitude, identification teaches. This is its precise meaning and function. It targets the formation of an intuitive knowledge about an existing and general reality considered through the intermediary of the image. The postural attitude is here one of 'comprehension.' It is, therefore, radically different from the behavior of evocation specific to the home-movie attitude, and also different, in many aspects, from the behavior of 'participation' that we will have the opportunity to study with respect to the fiction film.

Identification in the documentary attitude thus constitutes a kind of apprenticeship. We grasp and understand a certain number of typical behavioral forms with the explicit or implicit goal of knowing the 'how' and the 'why' of these representative modes of behavior belonging to a certain category of comportment. 
The individuals represented on the screen thus have little value as individuals, unless of course they are 'personalized' as in certain documentaries that have fictionalized elements or that relate to a specific person (such as Nanook). But, as a general rule, the individuals of the documentary film are anonymous beings who are seen as representing broader categories of individuals. Thus, in our example, the country doctor is not taken as a singular person but as one doctor among many, chosen from the group of country doctors as a representative sample of this group. It is therefore an anonymous being whose anonymous behavior we grasp, and who we relate to a set of individuals.

That is to say that, in this case, identificatory behavior does not imply any 'ego transference.' The 'ego' of the spectator and the film character remain in a relation of pure exteriority. In other words, we identify with the character to understand their behavior, but in no way do we try to be this character, who has no, or almost no, 'personality' for us. We remain ourselves in the process of grasping the modes of comportment illustrated by one or more anonymous, merely representative individuals. There is nothing similar, in this type of identification, to that by which we try to substitute ourselves for the other person, to become united with the other person, because it is another character, a hero, whom we have strongly 'valorized.' We will encounter this type of identification when we have to envisage a certain genre of fiction filmmaking.

Here it is only a question of apprehending impersonal behavior merely illustrated by an anonymous individual.

This is why we said that the spectator and the character remain in a relation of pure exteriority.

We have the structure and the meaning of identification in the documentary attitude. We also know that this identification does not imply an engagement of personal 'ego' in the character of the film. But above all, we know that, in the case that occupies us, it is a form of apprenticeship. We must now ask ourselves about the particularities of this form of apprenticeship, taking into account the non-presence of the object. In other words, what differentiates the formation of knowledge in a filmic situation from the formation of knowledge in real situations? Here, we can only give a tentative response to this rather marginal question, but it may nonetheless be suitable to address it, given the importance that it can take in the framework of the problems that audiovisual pedagogy poses to us.

Two elements retain our attention.

Firstly, let us note that, in a real situation, in contrast to what takes place in the filmic situation, our presence alongside the people with whom we identify implies a certain reciprocity in relations. 
We are always situated in a relationship with other people, and, at the same time that there is our view on another person, there is also the view of another person on us. Our presence alongside the other person is felt, and hones our attention as well as that of the other person. In short, we are in the midst of a real situation, and are concerned by other objects and people.

In a filmic situation, there is nothing of the sort. We apprehend reality 'from a distance' and our presence is absolutely not under question. It follows that we can develop a purer behavior of comprehension, because it is extracted and centered exclusively on the object.

On the other hand, however, we must also consider that, since we are not in a concrete, real situation - or rather, since we are not physically engaged in this situation, and since we are therefore not physically concerned by it, the reality considered through the intervention of the image does not have the density for us that its actual presence would, with all that this implies (particularly on the level of affectivity). We all know through experience that following dramatic events on the screen makes less of an 'impression' on us than seeing them in reality. This is because, in the cinema, we see things and events 'from a distance,' without truly being concerned by them. The reality targeted remains distant, and becomes 'disaffectivized.'

Thus, in our example, we can well understand the difficulties faced by the country doctor, we can even see them, but in a manner abstracted from reality. Consequently, we imagine what they are more than we really feel them. By 'imagine' we do not mean an intellectual operation, by which we represent to ourselves what these difficulties are. Rather, since we are not in a real situation, we can only 'play' what we would feel more deeply if we were present at the events and directly concerned by them.

It follows that this modality of apprenticeship that is identification in the documentary attitude offers the advantage of a comprehension that is more 'objective,' because it is extracted from the situation. Moreover, it remains impotent to render in all their density the affective resonances that are engendered by real contact with these events.

\section{c) Identification in the 'Fiction Attitude'}

We here reach the most important point of our analysis, since it is quite evident that the behavior that will be under discussion is by far the most characteristic of the filmic fact.

Along with identification in the home-movie attitude and identification in the documentary attitude, we have studied the forms of comportment 
corresponding to cinematic functions that are, when it comes down to it, rather secondary, if not de jure, then at least de facto.

Through the importance of its on-screen representation, as well as through its consumption by the broader public, fiction evidently constitutes the principal sector of film production. This is why we will accord special attention to the behavior solicited by fiction films.

Let us briefly recall the essence of what we have said with respect to the attitude taken when faced with a fiction film.

We know that, in the fiction film, the filmic datum does not refer to anything that exists. The filmic world, we said, closes in on itself in order to constitute itself as an autonomous reality. It is a quasi-world populated by quasi-presences, which we believe in without positing its existence. Our attention focuses on the image in its individuality. Correlatively, the activity of consciousness almost exclusively consists of acts of retention and protention, whose goal is to integrate at every present moment the set of passing events, and to project, on the basis of these present moments, future events. Thus, as we have seen, there is no longer any possibility of a detachment or a distanciation from the filmic reality. Consciousness is led to follow the story and cannot be detached from it.

How is the apprehension of perceived behavior realized within this particular attitude?

In other words, what is the meaning and the function of identification with the characters of a fiction film?

We know that, here, the perceived behavior is almost entirely cut off from existing reality. It only has meaning inside the film, within the action in the course of being shown. Thus, for example, when we follow the behavior of the hero in a Western, we obviously do not seek to represent what heroes in general do. Their existence is not even presumed. Simply, we wish to follow a story concerning a certain number of characters who interest us to the extent that they are significant to the imaginary story we wish to follow.

It is thus above all a matter of understanding the behavior perceived, not for what it is conducive to teaching us (as is the case in the documentary) but because it has a meaning within the story being told. This is the first function of identification. It exerts itself on all the characters, but is almost exclusive when it comes to secondary characters or, more precisely, characters who remain little 'affectivized.'

Let us explain this. We know that, in the beginning, identification is affectively ambivalent but that it is then oriented either towards sympathy 
or towards antipathy. The same, by the way, goes for the valorization or devalorization of characters.

And yet, in the cinema, there are characters who are strongly 'affectivized' - generally, they are the main characters - and others who are barely 'affectivized' at all (who are generally secondary characters). We will later discuss the manner in which this 'affectivization' is structured. For the moment, we will limit ourselves to describing the meaning of this identificatory behavior according to whether it is attached to characters who are 'affectivized' to a greater or a lesser degree.

When it comes to less 'affectivized' characters, identification is, as we said, exclusively a behavior of 'comprehension.' The behavior of these characters is simply apprehended for its signification in the action taking place. This is the case, for example, in the behavior of the German sentinel when the prisoners try to escape. This comportment is grasped insofar as it has a meaning in the unfolding of events, but we in no way 'participate' in it. On the contrary, this type of comportment remains 'external' in the sense that it is situated with respect to a character who we follow more particularly.

Thus, when we are dealing with secondary characters affectivized to a lesser degree, identification simply grasps the individual behavior on the basis of its meaning in the context of the film, and the relationship of the spectator to these characters is a relationship of pure exteriority.

The same, obviously, does not apply when we are dealing with more strongly 'affectivized' characters. In this case, identificatory behavior takes on more of an allure of 'participation.' But it will be useful to distinguish several levels of participation.

To schematize somewhat, we can distinguish participation in the modality of 'being-with' from participation in the modality of 'being-like.' It is hardly possible to differentiate the objective filmic content susceptible to inducing one or the other of these modalities. The personality of the spectator remains the principal determinant of the type of participation. Nonetheless, without any presumption of reality, it seems to us that certain categories of film, such as so-called 'psychological' films, do more to solicit our participation in the mode of 'being-with,' whereas the heroic genre and so-called 'adventure' films appear to induce a greater degree of participation in the mode of 'being-like.' We will refer to concrete examples.

Thérèse Desqueyroux by George Franju (1962, adapted from a novel by François Mauriac) offers us a typical example of the psychological film. Thérèse Desqueyroux, the title character, does not have the typical qualities of the hero of an adventure film. She is a character the likes of whom we 
often meet in daily reality, someone who finds herself confronted with real psychological and moral problems, such as they occur in real life.

In the course of the film, a certain sympathy is formed for the character of Thérèse Desqueyroux, a sympathy which derives from an understanding of her behavior, and which in turn solicits this understanding even more. This sympathy for Thérèse Desqueyroux results in our participation in her problems, her state of mind, and her behavior. In other words, identification here takes the allure of participation. I am 'with' Thérèse Desqueyroux in the sense that I share her life and her psychological troubles. But what is important to underscore is that, while participating in her existence, I remain situated with respect to her. In other words, I do not engage my personal 'ego' in the character. Thérèse Desqueyroux remains before me, in a relationship of exteriority. I live in connivance with her, in a sort of sympathetic complicity, but I remain a center of reference. As such, the story of Thérèse Desqueyroux does not become my story, since I do not have a tendency to fuse with her, to be 'like her.'

Rather, I am in solidarity with her behavior and her state of mind. I am with her, while remaining myself. This is what we fittingly call participation in the mode of 'being-with.'

In films presenting a 'hero,' or, in a more general manner, characters who are highly idealized or magnified - the hero of a Western, James Bond, etc. - participation can sometimes take on an entirely different allure.

Think, for example, of certain Western heroes, super-men who triumph over all obstacles and succeed in all their endeavors, both on the level of action and on a romantic level. This type of character offers to the audience the spectacle of a comportment, or rather, a highly idealized manner of being.

Not only do these characters provoke our sympathy, but, more than this, they are valorized to a very high degree.

We should clarify that valorization should not be understood as proceeding from a moral judgment, but rather as flowing from an intuitive apprehension of privileged comportment on the level of relations with another person. We have here the affective valorization of a comportment that appears as an ideal form of behavior.

It follows that participation in such comportment is often much more than mere solidarity. This is because participation takes on the allure of an attempt to 'be like' the hero. Here, there is identification in the narrow sense of the term. In other words, there is an attempted fusion with the highly valorized character. The ego tends to establish with the personality of the hero a relation not of exteriority but of belonging. The center of reference is no longer the ego of the spectator but the personality of the hero, and 
participatory behavior consists of an effort to be this personality. This is, therefore, participation in the mode of 'being-like.'

But we must maintain that this genre of participation brings with it certain limits that it is important to specify if we wish to avoid wasting our breath by producing a caricature of reality. This attempt to incorporate the hero leads, in effect, to an extremely complex state in which the spectator has a tendency to become another person while nonetheless remaining himself.

Let us try to elucidate this ambiguity and begin by further clarifying the link established through participation.

We said above that participation in the mode of being-like tends to establish a relation of belonging. But what, precisely, does this relation consist of? Here, we must be wary of abuses of language, because certain expressions - which we ourselves have utilized - such as 'fusion with the character,' 'transference of the ego into the character' or even 'forgetting oneself to live inside the character,' expressions which are frequently used in the literature dedicated to cinema, are only a very imperfect reflection of reality, exaggerating it or deforming it due to the words used to describe it. It thus appears necessary, lest we lapse into committing certain errors, to nuance the global meaning that these expressions contain. The problem is thus to specify the exact nature of the relations between the self (the spectator) and the other person (the character) which are established through participation.

First of all, what do we mean when we speak of 'forgetting oneself' with respect to the spectator?

This question requires us to clarify what we mean by the 'self.' We know that subjectivity is not closed in on itself, but is a relationship with the world and other people, that it is constitutionally intersubjective.

We also know that, in such conditions, it is in and through intersubjective relations that the 'self' and the other person reciprocally constitute each other through the interplay of identification and opposition. But this means, among other things, that, what I am for myself is, at the same time, necessarily what I am for other people, that the 'for-me' is indissolubly linked with the 'for-another.' When it comes down to it, this means that, in the process by which I constitute myself as a personal ego, I must constantly take into account what I signify for other people, through 'appearance' or exteriority, as well as through my position within a sociocultural milieu, which confers on me a signification in the eyes of other people that I have not chosen but that I must accept, and either take responsibility for or overcome.

These remarks will allow us to better understand what is meant by 'forgetting oneself.' 
Although constituted interiority must also accommodate exteriority (or being-for-another) within itself, because they are indissolubly linked with one another, this does not prevent it from sometimes escaping itself, at least on the imaginary level, and taking refuge in another exteriority, another being-for-another.

It is in the imaginary realm, indeed, that we can, for a certain length of time, abstract ourselves from the concrete conditions of our existence, and free ourselves from this signification for the other which we must always assume in real life, and it is in the imaginary realm that we can consequently try to install in our interiority another being-for-another linked to another apparition and other conditions of existence. The expression 'forgetting oneself' means nothing other than the bracketing of one's social being. We are now in a position to further clarify this 'relation of belonging' which we evoked earlier, and which we admitted was specific to participatory identification. This relationship is established between the interiority of the spectator and the exteriority of the character, between the for-oneself of the spectator and the being-for-another of the character.

The attempt to be 'like another person' is, in the end, an attempt to let dwell in one's interiority another apparition, another signification for another person. Correlatively, what the spectator targets in participatory identification is not the other person as a being endowed with an interiority, but as an exteriority, a being incarnated in a certain body realizing certain possibilities within a certain historical and social milieu. In a word, it is a special manner of being-in-the-world-and-with-other-people that the spectator seeks to integrate. In this behavior, the essential function of mimicry (posture) is precisely to make the external behavior of the character dwell in the interiority of the spectator, thereby constituting a link of belonging between the being-for-another of the latter and the being-for-oneself of the former.

It may be useful to illustrate all this with a concrete example.

On the screen, the standard Western hero - we are referring here to classical Westerns with a simple structure, and not to certain films of the same genre which have ambitions that more evidently reside on the psychological or social level-imposes his law on the evildoers, his strong personality on his posse, and his seductive powers on the heroines. Each of his actions reflects a privileged mode of being, a kind of mythical style of existence, which is consequently enviable in many aspects. As such, if the character seduces me, the intersubjective relation that makes me coexist with him is structured in the direction of a belonging of his conditions of existence to my interiority. I try to appropriate to myself his behavior 
and his manner of being. By mimetically imitating him, I try to feel the exteriority of the hero in my own interiority. If he vanquishes an enemy, I act as if I have overcome the bad guy. It can even happen that I anticipate his behavior, reacting to events before he does or correcting his actions.

In short, I participate in a privileged manner of being-in-the-world by making it my own.

We can now see what distinguishes this mode of participation from that which we have defined as a "participation in the mode of being-with." In this latter category, we do not only aim for an exteriority. Through the exteriority, we try to feel the interiority of the character, even while we maintain a distance from it in order to comprehend it. Simply put, there is a co-existence with the other person, who remains other in terms of their personal consciousness. By contrast, with participation in the mode of being-like, there is no co-existence with another person, but an attempt to make another behavior exist for us. We should also note in passing that heroic characters, those who encourage participation in the mode of beinglike, do not impose themselves as individuals, that is, as personal beings possessing their own interiority, but rather as pure behavior or, if you like, as pure exteriority. They provide us with ideal schemas of comportment more than inviting us to consider them as personal consciousnesses. Think of Tarzan or Zorro, to take the simplest cases, or even James Bond or Matt Helm. On the other end of the spectrum, those characters who do more to solicit our complicity, connivance, or comprehension (participation in the mode of being-with) impose themselves as individuals, and invite us to enter deeper into the mysteries of their interiority, rather than live vicariously through their actions. These characters include Thérèse Desqueyroux, Cleo (from Cléo de 5 à 7 [Cléo from 5 to 7 , Agnès Varda, 1962]), the hero from Bicycle Thieves, or St. Vincent de Paul from Monsieur Vincent (Maurice Cloche, 1947).

All these considerations put us in a good position to elucidate the limited and ambiguous aspects of the relationship established by participation in the mode of 'being-like.'

If, as we believe, this participation is an adherence of the personal ego to the exteriority of another person, we can understand that the link thereby established cannot be totally realized.

If he finds himself favored by the filmic situation - a situation which is, we must clarify, advantageous for the bracketing of my own conditions of existence - it remains the case that the character under consideration is still before me.

An insurmountable distance remains between him and me. Fundamentally, for participation to take place, I must be able to transport myself 
into the filmic world. But I cannot do so, and so I remain condemned to mime from my seat the role that I try to occupy in the universe of the film. This means that, no matter how much I may realize the belonging of my interiority to the exteriority of another person, I can only make it act from afar. I must act 'as if' I were in the place of the characters, 'as if' I possessed their bodies and possibilities. And yet, this 'as if,' imposed by the insurmountable distance between that behavior which remains inexorably before my own self, remains implicit for consciousness and renders the realization of the relationship impossible. This is because 'acting' at being like another person implies that, at the same time, I deny that I simply am this other person. In other words, this means that the 'participating' ego who can only 'pretend' remains implicitly conscious of its exteriority, since 'pretending' implies that we cannot forget but only feign to ignore our proper conditions of existence, and that feigning to ignore implicitly means recognizing.

Thus, escaping from the self is never total. It is only ever a game requiring a share of bad faith, an attempt to deceive oneself about one's own reality and make oneself believe something else.

In what we have called participation in the modality of 'being-with,' there is nothing of the sort, since this behavior is a form of co-existence - that is, the simple coming together of the self and the other person as different beings.

Hence, the difference between the two types of participation appears still more clearly, and this difference, we believe, deserves to be elucidated, since it indicates to us that the experience of the film is neither simple nor singular, that it moves, at times, in the direction of the understanding of the other person, and at other times in the direction of an escape into the other person, and that any psychological or sociological study of the function of film in the life of individuals and societies must necessarily take into account this diversification of experience.

\section{The Differentiation of Identification According to Different Characters}

Until now, we have spoken of filmic identification in general, without worrying too much about the manner in which it is differentiated according to the different characters of a film. And yet, we all know from experience that our identification with a character varies greatly depending on whether the character is central or secondary, strong or weak, moral or immoral, etc. How is this differentiation brought about? 
In other words, what is it that makes our relation to certain characters, in the course of a film, take on the allure of an intense participation, whereas for others, it is reduced to mere understanding?

We already partially responded to this question when we envisaged the problem of the different modalities of filmic identification, but it is doubtless apt now to return to this issue, by further systematizing the elements of an answer.

We have sometimes posed the problem of the structuring of identification according to different characters in terms of a choice, by the spectator, of a privileged individual who is identified with in an almost total manner. Subsequently, to justify this choice, it sufficed to appeal to one or another objective characteristic, discernible in the personality (or the character) and conducive to inviting the spectators to 'escape' or 'project' themselves into this character. Thus, we have invoked the physical beauty of the onscreen figure as an invitation to live for a time with the ideal appearance that we do not possess. Sometimes, too, we attributed the role of enabling intense participation to certain traits held in common by the actors and the spectators. If they find themselves faced with the physical or moral image that actors present to them, spectators have the opportunity to 'project' themselves into a cinematic 'alter ego.' Of course, the objective elements which, like physical beauty, arouse our escape into an ideal personality, or which, like the resemblance between the spectator and the actor, invite our participation through connivance or complicity, intervene, to a certain extent, in the choice that the spectators make.

On this matter, we should signal that, during a study aiming to clarify the impact on the audience of the film La Vie conjugale by André Cayatte (Anatomy of a Marriage, 1964), we were able to observe that certain spectators, having gone through problems similar to those encountered by the characters, took the side of one or the other of the characters, and stood up for them. Thus, everything leads us to believe that during the course of the film, these same spectators had 'projected' themselves, more than is normally the case, in what appeared to them as their own image.

We do not deny the importance of the objective elements which have here been in question, but, what seems erroneous to us, or in any case abusive, is the idea that we turn these elements into 'factors of identification,' that we establish a direct link between these elements and the choices of spectators.

First of all, this would considerably reduce the act of identification. As we have seen, it is not only a behavior of intense participation, but intervenes on every level of relational behavior. We therefore need to describe the 


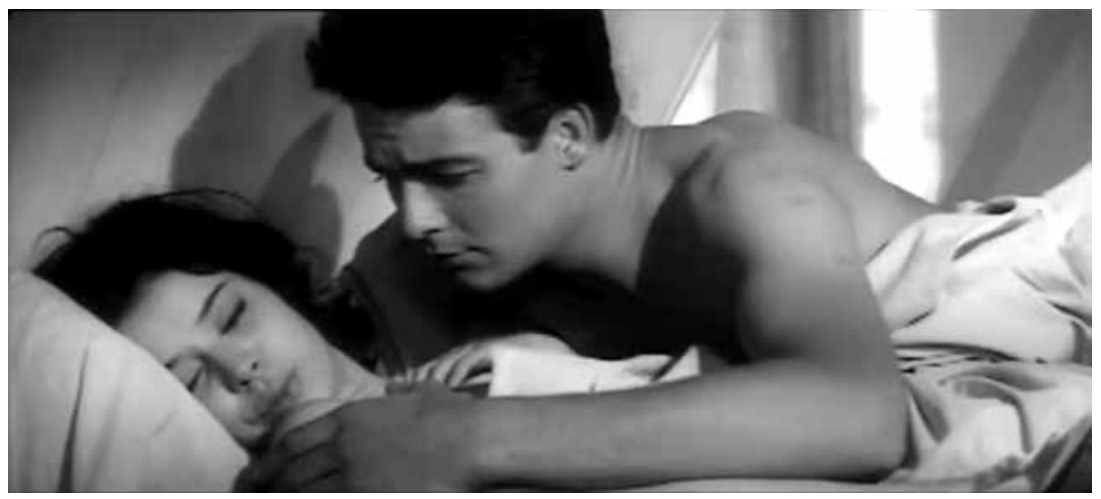

Fig. 6: Françoise (Marie-José Nat) and Jean-Marc (Jacques Charrier) in André Cayatte's Anatomy of a Marriage.

modalities of identification, more than defining privileged cases where it is realized to a high degree.

Subsequently, if there was a direct link, if physical perfection or resemblance automatically induces participation, it is hard to see why these elements do not function in an equal manner for characters who are apparently equal on the level of beauty, or on the level of possible similitudes with the spectators. For example, among the secondary characters gravitating around the main characters, there are often those whose physique or conduct might inspire the spectator. In the same manner, it is also hard to see why, in the hypothesis of a direct link between physical perfection and participation, certain stars do not exert the same hold from one film to the next. The cases are numerous wherein a star, who is generally adulated by the public in the majority of his films, loses, as a result of playing a new role in a situation that is unusual for him, his power of fascination. Thus, in Lost Command (Mark Robson, 1966), Maurice Ronet plays, alongside Alain Delon and Anthony Quinn, and in opposition to these two actors, a particularly antipathetic character, barely conducive to soliciting the participation of the spectator.

The manner in which we here discuss the attractive value of the 'objective' elements under consideration, can appear a little simplistic, but nonetheless shows that it is vain to try to establish direct links between participation and a visible trait of the characters independent of the context in which they are perceived. If the traits of the characters have any influence on identification, this cannot be in the absolute, but in relation to a certain context. This is why we find it illegitimate to pose the problem of the differentiation of identification in terms of the choices motivated by certain characteristics of the characters envisaged as isolated beings. 
In reality, if we attentively examine the film experience, we will see that the characters of a film are always perceived in relation to one another. They are characters-in-relation-to-other-characters. As we expressed at the beginning of this work, we do not perceive isolated subjectivities, but social beings perpetually in relation to one another and drawing their very definition from these relations. Likewise, characters perceived in the cinema are perceived as relational nodal points. They define themselves with respect to other characters and the objective elements (or rather 'objectifiable' elements) which characterize them, only have meaning in the social context specific to the film.

In fact, one of the reasons why we have sometimes sought the direct causes of intense participation in the objective traits of characters was very probably the constancy with which certain actors garnered the admiration of spectators. It was consequently tempting to attribute only to the elements that are apparently invariant from one film to another - the physique and the temperament taken by themselves - the direct reasons for the constancy of the fascination they exert on the crowd. But, when looking more closely, we can see that, what principally remains invariant, from one film to another, is the character played by these actors, a character who is always ratified by the social context of each of their films. Thus, in almost all films, Jean Gabin presents the image of a strong, slightly gruff personality, admitted as such and confirmed by his entourage.

Likewise, Brigitte Bardot, who has never ceased, since the beginning of her career, to play beautiful, erotic, and amoral young women, has always found herself in filmic situations from which she has drawn this signification of amoral and erotic beauty.

We can also say that her physique and temperament predispose her to this signification, but this is possibly because she plays the same role in life as she does on the screen, or, in other words, that, taking into account her innate physical attributes, the human relations of her real existence have been structured in a certain manner, and that it is this manner that has been reproduced on the screen in situations that confirm it.

In any case, we are still dealing with roles and situations, and with characters drawing a certain signification from a certain context, and not isolated personalities drawing from themselves, like a secretion, a certain power of attraction or repulsion.

Moreover, in contrast to actors restricted to a single persona, there are many others whose various appearances on the screen are so many compositions of characters having little or no relationship between them, and they acquire from this fact very different significations. 
In short, as we have said, film characters are always characters-in-relationto-other-characters who receive their signification from the social situations in which they are involved. It seems that it is on this basis that we must envisage the problem of the differentiation of identification according to different characters.

We must consider that, at the beginning of the film, all characters are simply apprehended by the spectator in roughly the same manner. We grasp this behavior and understand its meaning, but nothing is as yet well structured, since the relations between characters are still too imprecise. If, at this point, certain characters already appear as more sympathetic than others, we are still only dealing with a barely sketched out sentiment. This sentiment is doubtless predicated on a style of behavior that makes us presume an appearance that has either been glimpsed or, in the case of a well-known actor, valorized in other films, and that we are prepared to once again find a familiar role for them. But, up to this point, differentiation has only just been initiated. It is only later, in the course of the film, that identification is structured and differentiated into an intense participation, in the case of certain characters, or a simple comprehension, in the case of others.

The fact is that, during the unfolding of a film, that is, as the interactions between characters are intensified and specified, each one of them reveals their signification within the pattern that the ensemble of these characters constitutes.

Let us clarify things a little. As we have underscored, the spectator does not perceive isolated characters, but beings in relation with one another, characters-for-other-characters, or, alternatively, the manners that these different characters have of structuring their relations with other people.

In the course of the action they undertake, these manners of comportment are specified, and each one of them takes on a signification in relation to the others.

As this apprehension of significations is realized, the intersubjective relations between the spectator and the character are modified and concomitantly diversified.

In fact, the affectivity which, as we have seen, plays an essential role in identificatory behavior, invests the characters in a very different manner according to the significations that they reveal. Certain behavioral styles appear sympathetic, while others are apprehended as indifferent or antipathetic. Certain of them are valorized, while others are devalorized.

And yet, this affectivization and valorization of the characters will orient the form and intensity of identifications. We espouse the cause of 
sympathetic, valorized characters. Identification is crystallized around them, it is intensified and takes the allure of participation. As for the other characters, they are soon only apprehended through the main characters, to which we adhere almost exclusively. We grasp their behavior as having a meaning with respect to the chosen characters, and we often feel for them the same sentiments as those that they inspire in these same chosen characters.

At the risk of gross schematizing, we could summarize the complex process that we have just described in three successive phases, which can be delineated as follows:

1. Understanding of different characters.

Here, identificatory behavior merely grasps the meaning of on-screen behavior. Following this comprehension, each character takes on a certain signification with respect to the others.

2. Affectivization and valorization of the characters.

Certain modes of behavior are affectivized in the direction of sympathy and others in the direction of antipathy and indifference. Likewise, the same behavior is valorized or devalorized and remains indifferent on the level of its value.

3. Identification fixates on the sympathetic, valorized characters. It becomes participation.

The other characters are now only grasped through the main characters.

Let us try to illustrate this process by means of a concrete example chosen from a genre that is rather simple as far as the signification of characters is concerned: the Western. High Noon by Fred Zinnemann (1952), a Western that has become a classic, tells us the story of an aging sheriff at the end of his career, who finds himself suddenly constrained to carry out an imperative but dangerous task.

The drama begins at 10 o'clock in the morning. Will Kane, the sheriff, has just married, and is ready to once and for all leave the town in which he has conscientiously carried out his duties for many years. However, at this very moment, Kane learns that the train from the south will bring a dangerous outlaw (Frank Miller) to the township, whom Kane had earlier condemned to death. Already, three accomplices wait for Miller at the station. Up to this moment, and although the ensemble of characters has already begun to organize itself around Kane, the spectators limit themselves to understanding the situation and grasping the meaning of behavior specific to the different characters, who still have barely any signification on the affective level. 
But the rest of the action will increasingly orient our attention and affectivity on Kane: the sheriff, in the absence of a successor who will only assume his functions the following day, vainly tries to rustle up a posse of men to welcome the four 'desperados.' One by one, and for various reasons, his friends desert him. Even his wife abandons him. Everything is against him, and he will have to fight alone.

We can see how the identificatory behavior of the spectator is differentiated. Through the situation and the interaction between the characters, Kane's behavior is bestowed with a signification that induces affectivization and valorization, which results in identification being transformed into participation. On an affective level, we take his side, stand up for him. Our state of mind coincides with his own, and we 'experience' his behavior.

As for the other characters, they are primarily apprehended through Kane. Many of them (the townsfolk) are felt to be mediocre or cowardly, and Miller is seen as a mortal danger. Of course, even for these other characters, identification can move in the direction of a deeper comprehension. Kane's wife, for example, can certainly be the object of identification-comprehension. For proof, take this extract from a newspaper review, which can only be the result of enhanced identification:

Kane's wife. Her character is like that of the pastor. She belongs to the Quaker religion which forbids violence of any kind. She pushes her religious convictions to the extreme and coldly imagines leaving her husband, resorting to threats in order to put pressure on him. We should adopt a very nuanced judgement in the analysis of her behavior if we take into account, on the one hand, the depth of her religious convictions, and on the other hand the obligation she has, owing to her marriage, to understand and admit the point of view of her husband, who values doing one's duties.

We should also underscore that she was not born a Quaker, but had embraced the pacifist religion following a murder in her family, committed right before her eyes. This atrocious vision provoked a psychological shock in her. She sees nothing strange in the fact that a new shock (seeing her husband on the verge of being killed) should provoke a profound, instantaneous change in her feelings, and lead her to use violence in her turn in order to defend the man she never stopped loving...

Evidently, this type of analysis can only come from identificatory behavior which is based on comprehension, and which has been developed during 
a viewing of the film. But it is still the case that, for the vast majority of spectators, Kane's wife remains a 'peripheral' character understood through her relationship with Kane, the central character who not only solicits our understanding but also our participation.

Let us note that this participation will attain its culmination when Kane heads off in search of his enemies in order to do battle with them, a battle which he miraculously wins despite being greatly outnumbered.

We can now see more clearly how identification is structurally and functionally differentiated according to the various significations with which the different characters are endowed within the situation in which they are inserted.

We can also see the precise importance that we must attribute to the objective, isolable elements in the physical and moral personality of the actor. It is only in a situation or a social context in which physical beauty is valorizable that this beauty can intensify identification or orient it towards participation.

In the same manner, a possible resemblance between actor and spectator only acquires importance in and through its context. If we are dealing with a moral resemblance - that is, a resemblance that is translated through a similarity in comportment - this is evident. If we are dealing with a purely physical resemblance, everything depends, in our opinion, on the signification that the character in question takes in the context of the film. If the character is favorably situated, that is, if they are valorizable and conducive to inspiring sympathy, there is every reason to believe that this element of resemblance will orient our identification towards more intensity or participation. If, on the contrary, this same character is disadvantageously situated, it is rather certain that the element of resemblance will not in any fashion influence identificatory behavior.

In a word, the primordial element on the basis of which we must understand the type of identification that a character solicits is the signification that this character draws from their position in relation to the other characters.

Now, to avoid any confusion, it is essential to note that the process by which each of the characters draws their signification from the context is not something objective that would be uniquely situated within the film, and to which the spectator is simply subjected. In fact, in the final analysis, it is the spectator who attributes significations, and who projects these significations onto the different characters in order to subsequently affectivize them and valorize them in one sense or another. But what we have simply wanted to show is that this bestowal of signification is realized not 
through a direct effect of some kind of characteristic objectively readable in the personality of the actor or, more generally, the character taken in isolation, but rather through the apprehension by the spectator of a series of interactions between the characters, interactions that permit him to situate the characters with respect to one another and thus to attribute significations to them.

To put it differently, it is the spectator who, entering into intersubjectivity with each of the characters during the initial emergence of identification, and thus perceiving in each of them a certain mode of comporting themselves in relation to other people, or a mode of being for the other characters, will give a certain signification to this manner of being for other people.

This last remark elicits another question that will make us pose the problem of an objective approach to audience reactions. If it is true that it is definitively the spectator who is alone responsible for the significations accorded to the characters, do we not fall into a pure subjectivism, and are the reactions of the spectators not too individual, and thus too diverse, for the possibility of synthesizing them ever to be glimpsed?

We do not think so, since subjectivism does not necessarily signify a heterogeneity of perceptions and a dispersion of behavioral forms.

In fact, if the perception, identification, and attribution of significations essentially belongs to the subjective activity of the spectator, we must say that this subjective activity is largely guided by the author of the film.

In other terms, it is the director who solicits, to a large degree, the manner in which spectators structure their behavior.

When he makes a film, a director incarnates in behavior significations that he wants the spectators to recognize. He structures the relations between characters in such a way that each one of them is grasped by the spectators. He composes each behavioral act in such a way that it is perceived and felt by the spectators, just as he desires it to be. What is more, he disposes of numerous technical procedures conducive to highlighting the significations that he translates to the level of comportment (the scale of shots, rhythm, the soundtrack, etc.), so much so that, at the end of the day, he is the one who solicits and orients the manner in which the spectators must apprehend the characters and structure their behavior. Moreover, we should also remark that this solicitation of the author is exerted not through a critical consciousness, but, as we have seen earlier, through a 'captivated' consciousness, led to coincide with the filmic reality and thus without any distance from it.

It follows that the solicitation of the author takes the allure of a real shaping of the spectator's behavior and manner of perceiving. The psychological 
conditions of filmic perception are such that, in the course of viewing the film, a narrow relationship is established between the subjectivity of the director and the subjectivity of the spectator, with the latter being led to find the significations incarnated by the former, by means of the filmic content.

This is why subjectivism does not signify a dispersion of reactions. On the contrary, we now understand that, between the spectators of one and the same film, there exists a community of comportment and, extending our reasoning further, we can ask whether this behavioral community reinforces each individual's behavior through what they have in common. Indeed, everyone knows that the reactions of the isolated spectator seem rather different, and in any case timider, with respect to those of the spectator within a group, and it is easy to understand this. In the midst of other spectators whose reactions are perceptibly similar, every individual is confirmed in their own reactions, and gives free rein to them. Thus, within the group of spectators, there is a mutual reinforcement of reactions through what they have in common. We can say that, in addition to the intersubjective link tying each spectator to the author, and thanks to this link, there forms among the spectators in a single theater an anonymous intersubjective link, drawn from a contagion of reactions, and through which each individual has a vague feeling of solidarity with the crowd.

It is now important to note that the solicitation of the author can be exerted to different degrees. While particularly powerful in the majority of action films, it is often less spellbinding when it comes to films inspired directly by daily reality, 'psychological' films, or social-issues films.

Action films (the Western, the cloak-and-dagger film, the spy film, the adventure film, etc.) often only recount a story involving characters with a simple and clearly differentiated psychology (there are 'good guys' and 'bad guys,' brave men and cowards, etc.). Such films generally arouse in the spectator simple reactions, which are exactly those anticipated by the author, all the more so given that these films address a well-disposed audience, who only wish to be distracted by the antics of purely fictional heroes. But for other films, those in which characters with more complex psychologies bring with them a measure of ambiguity, it is obvious that the relationship between the spectator and the character, although it is broadly oriented by the author, is also nuanced according to the personality and the history of each party. We can think, for example, of the characters in films such as Hiroshima mon amour by Alain Resnais (1959), Jules et Jim by François Truffaut (1962), Thérèse Desqueyroux by Georges Franju, 81/2 by Federico Fellini (1963), Moderato Cantabile by Peter Brook (1960), and many others. The equivocal nature of these characters, with their complicated 
psychology rich in contradictions, leaves greater room for the initiative of the spectator, above all when the ambiguity is willfully maintained by the author (e.g. Anatomy of a Marriage by Cayatte).

In the end, we can see that the behavior of the spectator is organized in a very complex manner. We could now begin an analysis of the way in which, within a single subjectivity, the personal urges and the solicitations of the director are articulated. This analysis would doubtless require an elaboration that would be too long to be included in the present study.

Our project was to describe the broad outlines of spectatorial behavior, and to thereby furnish a useful canvas for a global comprehension of phenomena.

This said, we believe it is useful, as much to clarify our ideas as to form a conclusion, for us to briefly summarize the ideas developed in this chapter.

Identificatory behavior is structured in different ways according to the different characters of a film, and this is a function of the different significations that the spectator attributes to these characters. The attribution of signification is a subjective matter, but it finds itself broadly solicited by the author. Finally, this solicitation of the author can exert itself to varying degrees, depending on the type of film or, more generally, the will of the director.

\section{Chapter III: Towards Post-Filmic Behavior}

After studying the structures of the film experience, we would like to hazard a few hypotheses relating to the influence of filmic identification.

Here, of course, we can only summarily paint the broad brushstrokes of a tableau showing the principal repercussions of a film on the mental life and personality of the spectator. To put it simply, as much to manifest the possible utility of the preceding discussion as to initiate further study of the problem, we would like to open up certain perspectives to the analysis of the influence of the cinema. More precisely, based on what we have said of the film experience, we will try to explain the manner in which this experience can be prolonged in psychic life and, on this basis, formulate hypotheses about what it would be fitting to call post-filmic behavior.

We have seen that, in the case of fiction films, identification can take, at least when it is focused on the central characters, two rather different forms: participation in the mode of 'being-like' and participation in the mode of 'being-with.' 
We can take this observation as a starting point and formulate the hypothesis, which is a certitude for us, that the film will produce different effects according to whether one or the other of these modalities is realized.

Let us first envisage the case wherein the film has solicited participation in the mode of 'being-with.'

Let us recall that this modality of identification is not presented as a form of escape into the other person, but as a complicity, a connivance with the other person. In this specific case, the self and the other remain in a relationship of exteriority, in the sense that the spectator participates in the other person while still remaining the same self, and that they 'experience' the other person as different to their own self.

We could also say that the spectator takes possession of the other person in order to assimilate them, to live inside them even while their self remains the center of reference. What would remain of this participation?

It goes without saying that if the effects of this behavior are prolonged, then this will take place on the same level as participation itself, that is to say, on the level of the being-with-other-people, or, more generally, the comprehension of other people as others.

Can we see how?

If we interrogate the spectators upon exiting a movie theater, we can observe that, in general, they are incapable of saying much of any interest about the films and the characters they have just been following. At the very most, they can express a few vague impressions or sentiments, but they cannot clearly explain the film experience through which they have just lived.

We could thus say that, with respect to the characters and, on this basis, the film, they possess an intuitive knowledge, and this can be understood if we recall the specific nature of identification.

In its participatory form, as in all its other forms, identification is in fact motoric and mimetic in nature.

And yet, mimicry, we can recall, consists of a postural or psycho-muscular attitude that aims to reproduce the behavior of the other person in order to understand it.

What the spectator possesses at the end of the film is, therefore, not a conceptual knowledge situated on the level of rational thought, but a knowledge that is somehow 'bodily' in nature. In figurative terms, we can say that the spectator remains impregnated by the other person - possessing, that is, in the form of motoric or bodily traces, the behavior of the other person. 
If we add to this the fact that this behavior is now presented to the spectator as a complete whole, then we have the essence of the intuitive knowledge we spoke about earlier: a bodily knowledge relating to the global behavior of the other person understood as another person. Of course, we are here leaving to one side the possibility of a conceptual knowledge resulting from a possible reflection that takes place while the film is being screened. It is not very often that this type of reflection is realized and it is not, in any case, the habitual function of the film to induce it.

It now remains for us to examine how this intuitive knowledge will be resolved. In our opinion, it can follow two different evolutionary paths (not counting intermediary cases). In the first case, it can remain in a vague, intuitive state. In this case, although it is not reproduced at the level of conceptual thought, this knowledge can constitute an enrichment in the general framework of our real relations with other people. It can always re-emerge and serve as a point of reference in the understanding and appreciation of the other person. This intuitive knowledge, therefore, would be in addition to the traces left by the multiple identifications (in real or cinematic situations) taking place in the existence of subjectivity in order to constitute the complex interplay of intuitive references. Seeing the exact role and the relative importance of filmic references is, we believe, a fundamental problem of interest for reflection and research. This intuitive knowledge stemming from filmic identification can equally be the object of a more or less elaborated explanation. This happens when the spectator, for one reason or another, is led to conceptualize (that is, explain using verbal categories) the identificatory experience of another person.

The manner in which this conceptualization is realized posits numerous problems that are difficult to resolve.

How can a global knowledge of an intuitive nature flow into concepts? What is the role of the imagination and its power to refer to the scenes of the film in this passage from the intuitive to the verbal? What are the relations between the mimetic traces and the imagination within the process that leads to conceptualization? And what is the role of intelligence?

The solution to these problems would necessitate long analyses that are impossible to realize in the framework of this study.

Nonetheless, as nothing more than a pure suggestion, we can propose this: there is, initially, an intention to conceptualize, to translate into words the behavior about which we possess all the necessary data, but in an intuitive and thus globally undifferentiated state.

This intention produces an activity of conceptualization. In order to understand this activity, it is essential to note that the concept only ever 
teaches us about one aspect of the comportment to be explained. If we say, for example, that a given character is 'courageous' we only find one aspect of the behavior of the character in question, and we discard the rest of his personality. Moreover, the term 'courageous' is still very general and very vague. We would need other concepts to specify what type of courage we are dealing with. And others would be needed to explain other behavioral aspects. The conceptualization of behavior is thus progressively achieved by reviewing its different aspects, that is to say, by taking a wide range of perspectives on it - right until, if this is even possible, the globally intuitive knowledge we possessed in the beginning is exhausted.

We now have a better understanding of how the activity of conceptualization should be realized: it must proceed by stages, and successively envisage different levels of judgment (the moral level, the psychological level, the social level, etc.). That is, it must take different points of view towards the intuitive knowledge that it possesses.

But, having chosen the level on which they will pass judgment, the spectator must also be able to relate, in their imagination, to the behavior of the most significant characters, with respect to the point of view they have chosen, and they must relate this behavior to all kinds of other behavior which they have experienced, and which they will use as reference points, since, in fact, behavior only has meaning in relation to the behavior of others, to which it is opposed or with which it is identified. The meaning derived from these relations will then be explained with the use of a concept.

If we add to this the fact that speech is not a pure translation of what it signifies, but that it has a constitutive character, then we have an idea of the complexity of the problems that the conceptualization or, if you like, the accession to the explicit meaning of intuitive knowledge has. These problems - which, it must be said, we have only been able to briefly skim through from a distance - belong to general psychology rather than film psychology. If we have devoted a few words to general psychology, it is because we think that certain more specifically filmic questions closely relate to it, and that possible research into these questions should take it into account. This is the case, for example, with the problem of the specific qualities - if there are any - of the conceptualization of a datum of cinematic origin. On this matter, there are those who have expressed the opinion that film was conducive to revitalizing the conceptual apparatus, and to giving birth to more flexible verbal categories. Without fully subscribing to this hypothesis, we think that it would still be useful for research to focus on this question. 
In any case, whether it leads to conceptualization or not, it is in the domain of comprehending other people, or more generally on the level of being-withother-people that participation in the mode of being-with can prolong its effects. In all instances, this participation constitutes an enrichment, an experiential surplus. Defining the exact role and the manifestations of this experiential surplus is, in our opinion, a research perspective that could be of great interest.

We must now consider those cases in which the film has solicited participation in the mode of 'being-like.' Let us first recall that this modality of participation consists of an attempted escape into the highly idealized personality of the character. Between the self and the other person, there is no longer a relationship of exteriority, connivance, or complicity, but one of belonging. The other person (the character) is presented as an ideal behavioral schema, and the ego installs itself into this ideal schema. In short, the ego tends to escape into a highly valorized behavioral mode.

What might be the extensions of this escapist behavior in psychic life?

Here, as is the case when participation is realized in the mode of 'being-with,' it seems evident that post-filmic behavior will have the same signification as participation itself. In other words, it is the attempt to be like the idealized other person that the spectator prolongs beyond the limits of the film. We must now look at the manner and degree of this behavior. Lessons learnt from lived experience on the one hand, and some conclusions drawn from simple observation on the other hand incline us to distinguish, rather schematically, three major modalities of post-filmic comportment corresponding to three levels of behavior: oneiric behavior, ludic behavior and imitative behavior.

Let us consider the case wherein post-filmic behavior is situated on the oneiric level. We know from experience that a major part of the life of the imagination consists of dreaming, wherein the dreamer identifies with an unrealized self whose very unreality allows for the accomplishment of ideal actions usually made impossible by the contingencies of real life.

In other words, the imagination is often the favored site for the behavior of escaping the self.

What, therefore, should be so astonishing about the fact that filmic identification prolongs its effects in the imagination? It is indeed normal that the spectator who, for more than an hour, has vicariously experienced an ideal comportment, contrives to reproduce it in their dreams or fantasies. This is all the more true given that escapist film characters have something unreal or mythical about them, in perfect accord with the world of daydreaming. It is also all the more true given that the dream offers the dreamer the possibility 
of experiencing idealized filmic comportment with their own physical traits. The dreamer, in fact, places their own self in their daydreams, but in an unreal form. We can thus say that the cinema constitutes an aliment for oneiric activity. It is also a powerful stimulant, since the identification that is repeated for the multiple heroes who populate the cinematic universe constitutes a powerful inducement to daydreaming.

Filmic behavior can thus be continued and completed in oneiric behavior. But this is not its only extension. Participation in the modality of being-like can sometimes engender more active forms of behavior, even if they are still bracketed off from reality. This is true for ludic forms of behavior, which are a compromise form between pure oneiric comportment and comportment in reality. Such behavior can be primarily observed in children. It is expressed in child play, and can be interpreted as an attempt to incarnate, to play in real life, that which has a purely imaginary character. Like dreamers, 'players' project themselves into an unreal, often idealized 'ego,' with the difference, however, that they realize their unreal 'ego' in manifest and apparently real comportment. In a word, they act 'as if' their 'dreamed ego' was a 'real ego.' To the same extent and in the same manner as the dream, the cinema constitutes a kind of aliment for ludic activity. We only need to consider the enthusiasm with which children contrive to reproduce in their games all kinds of situations illustrated by fiction films. Childhood games are replete with cowboys and Indians, cops and robbers, heroic soldiers, and numerous other characters born from the mythology created, at least in part, by fiction films.

As active and manifest as it may be, ludic behavior nonetheless remains without any great relationship with real life. Play rests on a convention, and the player who acts 'as if' they were a hero, even if they are fascinated by this character, never forgets that it is simply an enjoyable diversion. In other words, players never confuse themselves with the characters they play. Once the game is over, they come back to their own selves without any difficulty.

This amounts to saying that, as in oneiric behavior, ludic behavior in no way participates in reality. It is a pure escape from reality.

The same goes for the behavior of imitation, whose most perceptible manifestations can be observed in fashion styles. The 'Brigitte Bardot look' was often spoken about during the time when her popularity was such that, among the female public, many believed they could gain the same powers of seduction by donning the same long, unkempt hair as the star. Likewise, the myth of James Dean resulted in a wider uptake of wearing blue jeans. More recently, we have been able to note in men's clothing all kinds of details borrowed from James Bond. The examples of this kind are 
numerous. In fact, throughout the history of fiction filmmaking, there is practically nothing in fashion that has not felt the influence, in one way or another, of the major stars, who are both loved and envied by the public.

Fashions borrowed from film stars incontestably attest to the existence of imitative behavior, but they are only a socialized and, all in all, a rather superficial manifestation of this phenomenon.

If we question the meaning of imitative behavior on the purely individual level, we can propose this: imitation consists of behavior aiming to reproduce the idealized behavior of others, with the goal of appropriating the signification attached to this behavior. Thus defined, imitation is not fundamentally different from oneiric behavior and ludic behavior. In all cases, we still find the same desire to be like the idealized other. However, whereas dreams and play realize this desire in an imaginary manner, within the sectors of activity operative in real life, imitative behavior, for its part, attempts to realize it in reality.

In other words, imitation tends to realize the dreamed ego in the real ego. The dreamer or the player still kept in mind the distinction between the imaginary ego and the real ego. Or rather, their activity was based on this distinction. The imitator, by contrast, contrives to fuse the two.

The problem is thus to know whether this fusion is capable of being realized, whether it is structuring or destructuring.

This is not the place to treat this problem, which requires a discussion that would be too long for this study. Nonetheless, out of a concern for being even a little bit complete, we can, as a pure hypothesis, try to sketch out an answer.

If it is true, as we have maintained throughout this book, that man is a being who is relational right from the start, and that it is in and through intersubjective relations that the personal ego is constituted, if, in other words, we are nothing other than what we are for other people, then we can say that imitation can be structuring, insofar as the modifications of behavior that it engenders are conducive to being ratified by the gaze of the other. Conversely, it would be destructuring if the signification that the imitator tries to incarnate does violence to the signification constituted by other people.

In the latter case, imitation can doubtless have dangerous consequences for the mental equilibrium of the individual. In fact, it is constantly experienced as a vain endeavor unavoidably doomed to failure. Taking refuge in a character is a form of alienation that cannot be approved by other people. It can consequently result in aggression towards other people, or a detachment from reality, a withdrawal into the self and an escape into the 
imaginary. In short, it is divorced from real intersubjective relations. We can glimpse the consequences of this, but this is not the place to talk about them. In any case, if there is a place to elaborate a pathology of post-filmic behavior, it seems that we should look in this direction.

By relying on what we have been able to discern of the film experience, we have tried to highlight certain interesting perspectives for the study of post-filmic comportment.

In doing so, we have occasionally indicated certain problems that should, in our opinion, arouse the attention of the researcher. But we are also aware that the number of these problems undoubtedly exceeds what we have been able to discuss. The forms and consequences of these manifestations will doubtless be more clearly elucidated with the aid of multiple, painstaking observations.

Whatever the case may be, we think that it is on the basis of a reading or sufficiently elaborated description of the film experience as such that research in the field of cinema should formulate its hypotheses and construct its methods of observation. In the end, this is what we have wished to show in this last chapter. 